\title{
Ang-(1-7) protects HUVECs from high glucose-induced injury and inflammation via inhibition of the JAK2/STAT3 pathway
}

\author{
JIANFANG CHEN ${ }^{1 *}$, WEI ZHANG ${ }^{2 *}$, QING XU ${ }^{2}$, JHHUA ZHANG $^{3}$, WEI CHEN $^{4}$, ZHENGRONG XU $^{4}$, \\ CHAOSHENG $\mathrm{LI}^{4}$, ZHENHUA WANG ${ }^{4}$, YAO ZHANG ${ }^{1}$, YULAN ZHEN ${ }^{5}$, \\ JIANQIANG FENG $^{6}$, JUN CHEN $^{4}$ and JINGFU CHEN ${ }^{7}$ \\ ${ }^{1}$ Guangdong Medical University, Zhanjiang, Guangdong 524023; ${ }^{2}$ Department of Cardiology, \\ Huangpu Division of The First Affiliated Hospital, Sun Yat-sen University, Guangzhou, Guangdong 510700; \\ ${ }^{3}$ Department of Endocrinology, Shanxian Central Hospital of Shandong Province, Shanxian, Shangdong 274300; \\ ${ }^{4}$ Department of Cardiology, The People's Hospital of Baoan Shenzhen, Shenzhen, Guangdong 518100; \\ ${ }^{5}$ Department of Oncology, The Third People's Hospital of Dongguan City, Dongguan, Guangdong 523326; \\ ${ }^{6}$ Department of Physiology, Zhongshan School of Medicine, Sun Yat-sen University, Guangzhou, Guangdong 510080; \\ ${ }^{7}$ Department of Cardiovascular Medicine and Dongguan Cardiovascular Institute, \\ The Third People's Hospital of Dongguan City, Dongguan, \\ Guangdong 523326, P.R. China
}

Received December 19, 2016; Accepted January 23, 2018

DOI: $10.3892 / \mathrm{ijmm} .2018 .3507$

\begin{abstract}
Angiotensin (Ang)-1-7, which is catalyzed by angiotensin-converting enzyme 2 (ACE2) from angiotensin-II (Ang-II), exerts multiple biological and pharmacological effects, including cardioprotective effects and endothelial protection. The Janus kinase 2 (JAK2)/signal transducer and activator of transcription 3 (STAT3) pathway has been demonstrated to be involved in diabetes-associated cardiovascular complications. The present study hypothesized that Ang-(1-7) protects against high glucose (HG)-induced endothelial cell injury and inflammation by inhibiting the JAK2/STAT3 pathway in human umbilical vein endothelial cells (HUVECs). HUVECs were treated with $40 \mathrm{mmol} / \mathrm{l}$ glucose $(\mathrm{HG})$ for $24 \mathrm{~h}$ to establish a model of HG-induced endothelial cell injury and inflammation. Protein expression levels of p-JAK2, t-JAK2,
\end{abstract}

Correspondence to: Dr Jun Chen, Department of Cardiology, The People's Hospital of Baoan Shenzhen, 25 Yu An Er Road, Baoan, Shenzhen, Guangdong 518100, P.R. China

E-mail: szcjun@126.com

Dr Jingfu Chen, Department of Cardiovascular Medicine and Dongguan Cardiovascular Institute, The Third People's Hospital of Dongguan City, 1 Xianglong Road, Dongguan, Guangdong 523326, P.R. China

E-mail: chenjf-sums@hotmail.com

*Contributed equally

Key words: angiotensin-(1-7), human umbilical vein endothelial cells, high glucose, injury, inflammation, Janus kinase 2/signal transducer and activator of transcription 3
p-STAT3, t-STAT3, NOX-4, eNOS and cleaved caspase-3 were tested by western blotting. CCK- 8 assay was performed to assess cell viability of HUVECs. Apoptotic cell death was analyzed by Hoechst 33258 staining. Mitochondrial membrane potential (MMP) was obtained using JC-1. Superoxide dismutase (SOD) activity was tested by SOD assay kit. Interleukin (IL)-1 $\beta$, IL-10, IL-12 and TNF- $\alpha$ levels in culture media were tested by ELISA. The findings demonstrated that exposure of HUVECs to HG for $24 \mathrm{~h}$ induced injury and inflammation. This injury and inflammation were significantly ameliorated by pre-treatment of cells with either Ang-(1-7) or AG490, an inhibitor of the JAK2/STAT3 pathway, prior to exposure of the cells to HG. Exposure of the cells to HG also increased the phosphorylation of JAK2/STAT3 (p-JAK2 and p-STAT3). Increased activation of the JAK2/STAT3 pathway was attenuated by pre-treatment with Ang-(1-7). To the best of our knowledge, the findings from the present study provided the first evidence that Ang-(1-7) protects against HG-induced injury and inflammation by inhibiting activation of the JAK2/STAT3 pathway in HUVECs.

\section{Introduction}

The incidence of diabetes mellitus (DM) is estimated to rise to $7.7 \%$ by 2030 globally (1) and is predicted to affect $591,900,000$ individuals by 2035 (2). DM is a major and increasing health problem worldwide due to its increasing incidence, which can lead to a variety of complications, including diabetic retinopathy, diabetic nephropathy, diabetic neuropathy, diabetic foot and cardiovascular complications. Of note, cardiovascular complications are the major cause of diabetes-associated mortality (3). The vascular endothelium is central to the pathogenesis of diabetic complications, with vascular endothelial cells mainly involved in maintaining endothelial dysfunction; 
cardiovascular homeostasis is considered an important factor in the pathogenesis of diabetes-associated vascular complications $(4,5)$. Studies have revealed that hyperglycemia induces numerous pathological changes in vascular endothelial cell injury, including oxidative stress (6), inflammation (7), increased endothelial cell apoptosis $(6,8)$ and mitochondrial membrane permeabilization (9). However, the associated molecular mechanism by which hyperglycemia results in vascular endothelial cell injury in DM remains to be elucidated.

As one of four protein-tyrosine kinases, Janus kinase (JAK)1, JAK2, JAK3 and Tyk2, JAK2 is an essential factor in cellular proliferation, differentiation, survival and senescence. JAK2 also regulates other signaling molecules, including the RAS, signal transducer and activator of transcription (STAT)5, STAT3 and phosphoinositide 3-kinase/Protein kinase B (PI3K/AKT) pathways (10). STAT3 is a member of the STAT family (STAT1, STAT2, STAT3, STAT4, STAT5a, STAT5b and STAT6), and its phosphorylation is induced by the activation of JAK2; phosphorylated (p-)STAT3 forms a dimer and translocates into the nucleus from the cytoplasm, where it binds to related sequences and alters the expression of various target genes. Therefore, the JAK2/STAT3 pathway is gradually being recognized as a membrane-to-nucleus pathway for a variety of stimulating responses in vitro and in vivo (11-13). Accumulating evidence has shown that the JAK2/STAT3 pathway is a cell survival signal, which contributes to cell proliferation, differentiation, growth and apoptosis (14-16). The JAK2/STAT3 pathway is also important in the progress of cardiovascular diseases. Manea et al (17) demonstrated that the JAK2/STAT3 pathway is a crucial regulator of the response of EAhy926 endothelial cells to diabetes-associated cardiovascular dysfunction. Hyperglycemia increases angiotensin (Ang)-II-induced vascular smooth muscle cell proliferation by increasing JAK2/STAT3 pathway transduction (18). These findings indicate that the JAK2/STAT3 pathway is important in cardiovascular diseases and endothelial dysfunction. However, the effects of the JAK2/STAT3 pathway on high glucose (HG)-induced endothelial dysfunction in vivo, and the associated mechanisms, remain to be elucidated.

There has been increasing focus on the protective effects of Ang-(1-7) against hyperglycemia-induced cardiovascular complication. The secretory level of plasma Ang-(1-7) was demonstrated to be low in patients with diabetic-induced cardiac dysfunction (19). The expression level of angiotensin-converting enzyme 2 (ACE2), which is responsible for the tissue degradation of Ang-II into Ang-(1-7), was also observed to be decreased in patients with diabetes (20). An increase in the expression levels of ACE2 markedly improved control of blood glucose levels and alleviated glomerular injury in streptozotocin (STZ)-induced diabetic mice (21), and Ang-(1-7) was reported to exert protective effects against diabetes-induced cardiovascular events $(22,23)$. In addition, the Ang-(1-7) and ACE2/Ang-(1-7)/Mas receptor axis was revealed to have additional beneficial effects in preventing diabetes-induced cardiac dysfunction (24). These findings indicate that Ang-(1-7) is closely associated with hyperglycemia-induced cardiovascular dysfunction. However, the underlying mechanisms between Ang-(1-7) and hyperglycemia-induced cardiovascular dysfunction remain to be fully elucidated.
A previous study reported that Ang-(1-7) produced an inhibitory effect on the activation of JAK2/STAT3 (25). In diabetic nephropathy, Ang-(1-7) exerts renoprotective effects on diabetic nephropathy via inhibiting the STAT3 pathway, apparent as a reduction in inflammation, fibrosis, oxidative stress and lipotoxicity (26). The present study tested the hypothesis that exogenous Ang-(1-7) protects human umbilical vein endothelial cells (HUVECs) against HG-induced injury and inflammation by inhibiting the JAK2/STAT3 pathway.

\section{Materials and methods}

Materials. Ang-(1-7) was purchased from Sigma; Merck KGaA (Darmstadt, Germany) and stored at $-20^{\circ} \mathrm{C}$. The following 2',7'-dichlorofluorescein diacetate (DCFH-DH), Hoechst 33258, 5',6,6'-tetrachloro-1,1',3,3'-tetraethyl-imidacarbocyanine iodide (JC-1) and AG490 (an inhibitor of the STAT3/JAK2 pathway) were obtained from Sigma-Aldrich; Merck KGaA). The Cell Counting Kit-8 (CCK-8) was supplied by Dojindo Molecular Technologies, Inc. (Kumamoto, Japan). Fetal bovine serum (FBS) and Dulbecco's modified Eagle's medium (DMEM) were purchased from Gibco; Thermo Fisher Scientific, Inc. (Waltham, MA, USA). Anti-p-STAT3 antibody (cat. no. SAB4300033), anti-total (t-)STAT3 antibody (cat. no. SAB4300708), anti-p-JAK2 antibody (cat. no. SAB4300124), anti-t-JAK2 antibody (cat. no. SAB4501599), anti-caspase-3 antibody (cat. no. C5737) anti-NADPH oxidase 4 (Nox4) antibody (cat. no. SAB4503153) and anti-endothelial nitric oxide synthase (eNOS) antibody (cat. no. N2643) were supplied by Cell Signaling Technology, Inc. (Boston, MA, USA), horseradish peroxidase (HRP)-conjugated secondary antibody (cat. no. KC-5A08) and a BCA protein assay kit were obtained from KangChen Biotech, Inc. (Shanghai, China). Enhanced chemiluminescence (ECL) solution was purchased from Nanjing KeyGen Biotech Co., Ltd. (Nanjing, China). The reagents for reverse transcription-quantitative polymerase chain reaction (RT-qPCR) analysis was obtained from Invitrogen; Thermo Fisher Scientific, Inc.).

Cell culture and treatments. The HUVECs were supplied by Sun Yat-sen University Experimental Animal Center (Guangzhou, China). The HUVECs were cultured in DMEM supplemented with $10 \%$ FBS under an atmosphere of $5 \% \mathrm{CO}_{2}$ and $37^{\circ} \mathrm{C}$ with $95 \%$ air.

To establish a model of HG-induced HUVEC injury, the cells were cultured in DMEM ( $5.5 \mathrm{mM}$ glucose) for $12 \mathrm{~h}$ prior to the administration of $40 \mathrm{mM}$ glucose (final concentration) for $24 \mathrm{~h}$. The glucose concentration of the control group was $5.5 \mathrm{mM}$. To investigate the protective effect of exogenous Ang-(1-7) against HG (40 mM glucose)-induced injury, the cells were seeded at a density of $1 \times 10^{4} / \mathrm{ml}$ and treated with $\mathrm{HG}$ in the presence or absence of Ang-(1-7) for $24 \mathrm{~h}$ at $37^{\circ} \mathrm{C}$. In order to examine whether the STAT3/JAK2 pathway contributed to the protective effects of Ang-(1-7), and to further determine the mechanisms underlying the protective effects of Ang-(1-7), the HUVECs at a density of $1 \times 10^{4} / \mathrm{ml}$ were co-treated with HG, $2 \mu \mathrm{mol} / 1$ Ang-(1-7) and $20 \mu \mathrm{mol} / 1 \mathrm{AG} 490$ (an inhibitor of the STAT3/JAK2 pathway), and incubated at $37^{\circ} \mathrm{C}$. 
RNAinterference.HUVECs were transfected at $70 \%$ confluency using Lipofectamine transfection reagent (Life Technologies; Thermo Fisher Scientific, Inc.), with siRNA against NLRP3 (Ribo Biotechnology, Shanghai, China) or a physiologically irrelevant negative control siRNA. The siRNA sequences used in the present study were as follows: Sense, 5'-GCUUCAGCC ACAUGACUUUTT-3'; and antisense, 5'-AAAGUCAUGUGG CUGAAGCTT-3'. Each siRNA was dissolved in nuclease-free water to achieve a final concentration of $20 \mu \mathrm{M}$. A total of $5 \mu \mathrm{l}$ siRNA $(20 \mu \mathrm{M})$ and $5 \mu \mathrm{l}$ Lipofectamine were added to a $500 \mu \mathrm{l}$ buffer system. The mixtures were kept at room temperature for $30 \mathrm{~min}$ to form complexes, and equal amounts were added into wells of a 6 -well plate. The cultures were incubated at $37^{\circ} \mathrm{C}$ in a $5 \% \mathrm{CO}_{2}$ incubator. The medium was replaced after $12 \mathrm{~h}$ with DMEM without the presence of siRNA or transfection reagent. Cells were collected at $12 \mathrm{~h}$ for analyses.

Western blot analysis. Following the indicated treatments, the HUVECs were harvested using a cell scraper and lysed with cell lysis solution (Beyotime Institute of Biotechnology, Haimen, China), at $4^{\circ} \mathrm{C}$ for $30 \mathrm{~min}$. The total proteins were quantified using the BCA protein assay kit. Loading buffer was added to the cytosolic extracts and boiled for $5 \mathrm{~min}$. Equal quantities of supernatant from each sample (20 $\mu \mathrm{g}$ were fractionated by $10 \%$ sodium dodecyl sulphate-polyacrylamide gel electrophoresis, following which the total proteins were transferred onto polyvinylidene difluoride membranes. The membranes were blocked with $5 \%$ fat-free milk for $60 \mathrm{~min}$ in fresh blocking buffer containing $0.1 \%$ Tween 20 in Tris-buffered saline (TBS-T) at room temperature, and incubated with either anti-p-STAT3 (1:1,000 dilution), anti-t-STAT3 (1:1,000 dilution), anti-Nox4 (1:1,000 dilution), anti-p-JAK2 (1:1,000 dilution), anti-t-JAK2 (1:1,000 dilution), anti-caspase-3 (1:1,000 dilution) and anti-eNOS (1:1,000 dilution) in freshly prepared TBS-T with $3 \%$ fat-free milk, overnight with gentle agitation at $4^{\circ} \mathrm{C}$. The membranes were then washed for 15 min with TBS-T and incubated with horseradish peroxidase (HRP)-conjugated goat anti-rabbit secondary antibody (Kangchen Biotech, Inc.), at a 1:3,000 dilution, in TBS-T with $3 \%$ fat-free milk for $90 \mathrm{~min}$ at room temperature. The membranes were then washed three times with TBS-T for $15 \mathrm{~min}$ and the immunoreactive signals were visualized using an ECL detection. In order to quantify protein expression, the X-ray films were scanned and analyzed with ImageJ $1.47 \mathrm{i}$ software (National Institutes of Health, Bethesda, MA, USA). The experiment was repeated three times.

Measurement of cell viability. The HUVECs were seeded in 96-well plates at a concentration of $1 \times 10^{4} / \mathrm{ml}$, and incubated at $37^{\circ} \mathrm{C}$, following which a CCK-8 assay was used to assess the cell viability of HUVECs. Following the indicated treatments, $10 \mu \mathrm{l}$ CCK-8 solution at a $1 / 10$ dilution was added to each well and the plate was incubated for $1.5 \mathrm{~h}$ in the incubator. The absorbance at $450 \mathrm{~nm}$ was determined using a microplate reader (Molecular Devices LLC, Sunnyvale, CA, USA). The mean optical density (OD) of three wells in the indicated groups was used to calculate the percentage of cell viability according to the following formula: Cell viability $(\%)=(\mathrm{OD}$ treatment group/OD control group) x $100 \%$. The experiment was performed five times.
Hoechst 33258 nuclear staining for the analysis of apoptosis. Apoptotic cell death was analyzed using Hoechst 33258 staining followed by photofluorography. Firstly, the HUVECs were plated in $35 \mathrm{~mm}$ dishes at a density of $1 \times 10^{6}$ cells/well. Following the indicated treatments, the cells were fixed with $4 \%$ paraformaldehyde in $0.1 \mathrm{~mol} / 1$ phosphate-buffered saline (PBS; pH 7.4) for $10 \mathrm{~min}$ at $4^{\circ} \mathrm{C}$. The slides were washed 5 times with PBS. Following staining by incubation with $5 \mathrm{mg} / \mathrm{ml}$ Hoechst 33258 for $30 \mathrm{~min}$, the cells were washed 5 times with PBS. Finally, the cells were visualized under a fluorescence microscope (Bx50-FLA; Olympus Corporation, Tokyo, Japan). Viable HUVECs exhibited a uniform blue fluorescence throughout the nucleus and normal nuclear size, whereas apoptotic HUVECs demonstrated condensed, distorted or fractured nuclei. The experiment was repeated 5 times.

Examination of intracellular reactive oxygen species (ROS) generation. Intracellular ROS generation was determined by the oxidative conversion of cell-permeable oxidation of DCF-DH to fluorescent DCF. The HUVECs were cultured on a slide with DMEM. Following the above treatments, the slides were washed twice with PBS. Subsequently, $10 \mu \mathrm{mol} / \mathrm{l}$ DCFH-DA solution in serum-free medium was added to the slides, and the cells were incubated at $37^{\circ} \mathrm{C}$ for a further $30 \mathrm{~min}$. The slides were washed 5 times with PBS, and DCF fluorescence was measured over the entire field of vision using a fluorescence microscope connected to an imaging system (BX50-FLA; Olympus Corporation). The mean fluorescence intensity (MFI) from five randomly selected fields was measured using Image J 1.47i software and the MFI was used as an index of the level of ROS. The experiment was repeated 5 times.

Measurement of the mitochondrial membrane potential $(M M P)$. The MMP was determined using the fluorescent dye, JC-1, a cell-permeable cationic dye, which preferentially enters mitochondria based on the highly negative MMP. Depolarization of MMP results in a loss of MMP from the mitochondria and a decrease in green fluorescence. The HUVECs were cultured on a slide with DMEM at a density of $1 \times 10^{6}$ cells/well. Following the indicated treatments, the slides were washed 3 times with PBS; and the cells were incubated with $1 \mathrm{mg} / 1 \mathrm{JC}-1$ at $37^{\circ} \mathrm{C}$ for $30 \mathrm{~min}$ in the incubator, washed briefly 3 times with PBS, and air-dried. The fluorescence was measured over the entire field of vision using a fluorescent microscope connected to an imaging system (BX50-FLA). The MFI of JC-1 from three randomly selected fields was analyzed using Image J 1.47i software, and the MFI was measured as an index of the levels of MMP. The experiment was repeated 3 times.

Measurement of superoxide dismutase (SOD) activity. SOD activity was analyzed using an SOD assay kit. Following the indicated treatments, the HUVECs were washed using PBS and lysed in ice-cold $0.1 \mathrm{M}$ Tris/ $\mathrm{HCl}(\mathrm{pH} 7.4)$ containing $0.5 \%$ Triton, $5 \mathrm{mmol} / 1 \beta$-mercaptoethanol and $0.1 \mathrm{mg} / \mathrm{ml}$ phenylmethylsulfonyl fluoride. The lysates were clarified by centrifugation at $14,000 \times \mathrm{g}$ at $4^{\circ} \mathrm{C}$ for $5 \mathrm{~min}$ and cell debris was discarded. SOD activity was detected using a commercial SOD Assay kit according to the manufacturer's protocol 
(Sigma-Aldrich; Merck KGaA). The absorbance values at $450 \mathrm{~nm}$ were measured using a microplate reader. The experiment was repeated 3 times.

Enzyme-linked immunosorbent assay (ELISA) for the detection of interleukin (IL)-1 $\beta, I L-10, I L-12$ and tumor necrosis factor (TNF)- $\alpha$ in culture supernatant. The HUVECs were seeded at $1 \times 10^{4}$ cells/well and cultured in 96-well plates. Following the indicated treatments, the levels of IL-1 $\beta$, IL-10, IL-12 and TNF- $\alpha$ in culture media were analyzed using ELISA according to the manufacturer's protocol. The experiments were repeated 5 times.

$R T-q P C R$ analysis. Total cellular RNA was extracted from cell cultures using TRIzol reagent (Invitrogen; Thermo Fisher Scientific, Inc.) according to the manufacturer's protocol. The extracted RNAs were DNase-treated with RQ1 RNase-Free DNase (Promega Corporation, Madison, WI, USA). First strand cDNA was prepared using Moloney Murine Leukemia Virus Reverse Transcriptase (M-MLV RT; cat. no. 1701; Promega Corporation). The RT-qPCR analysis was performed using the Rotor-Gene ${ }^{\mathrm{TM}}$ SYBR Green PCR kit (Qiagen $\mathrm{GmbH}$, Dusseldorf, Germany) and the QuantiNova SYBR Green PCR kit (Qiagen GmbH) on a Rotor-Gene 6000 Rotary Analyzer (Qiagen $\mathrm{GmbH}$ ), and determined using Rotor-Gene 6000 software version 2.3.3 (Qiagen $\mathrm{GmbH}$ ). For each assay, a total of $8 \mathrm{ng}$ cDNA was added to a final reaction volume of $25 \mu \mathrm{l}$ containing $1 \mathrm{X}$ Rotor-Gene SYBR Green PCR master mix or QuantiNova SYBR Green PCR master mix and $1 \mu \mathrm{M}$ of each forward and reverse primer. Quantitative gene amplifications were performed using the following thermocycling conditions: Initial denaturation for $5 \mathrm{~min}$ at $95^{\circ} \mathrm{C}$, 40 cycles of denaturation at $95^{\circ} \mathrm{C}$ for $5 \mathrm{sec}$, and annealing and extension at $60^{\circ} \mathrm{C}$ for $20 \mathrm{sec}$. The glyceraldehyde-3-phosphate dehydrogenase (GAPDH) gene was used as endogenous control (or reference gene). A non-template reaction was used as a negative control. Three replicates were performed for all analysis.

The selection of the threshold intensity was set at a fixed intensity on the log-linear phase of the amplification curve for all the samples tested. Validation experiments, which included the generation of standard curves using a series of diluted cDNA samples, were performed to ensure primer efficiency, and target and reference gene amplification compatibility. Melt curve analysis and conventional agarose gel analysis were used alongside to verify the presence of a single amplicon. An interassay calibration scheme was used to minimize loading variation and to detect possible contamination with the inclusion of duplicate reactions and 'no-template' control, respectively, in each qPCR assay. Relative expression levels of the gene of interest were calculated using $2^{-\Delta \Delta C q}$ method (27). All samples were normalized to GAPDH as the endogenous control (28).

The primers used were as follows: STAT3, forward 5'-CTT TGAGACCGAGGTGTATCACC-3'; and reverse 5'-GGT CAGCATGTTGTACCACAGG-3'; JAK2, forward 5'-CCG GAATTCGCTTTGAGTCGGTTTCTCCGGTTCC-3'; and reverse 5'-TGCTCTAGACCTCATGCAGTCGCTGAATAA GTCC-3'. GAPDH, forward, 5'CCACCCATGGCAAATTCC ATGGCA3'; and reverse 5'TCTAGACGGCAGGTCAGGTCC ACC 3 !
Statistical analysis. All data are presented as the mean \pm standard error of the mean. Differences between groups were analyzed using one-way analysis of variance with SPSS 13.0 (SPSS, Inc., Chicago, IL, USA) software, and followed by an LSD post hoc comparison test. $\mathrm{P}<0.05$ was considered to indicate a statistically significant difference.

\section{Results}

Ang-(1-7) and AG490 attenuate HG-induced decreased cell viability in HUVECs. The HUVECs were treated with different concentrations of glucose $(10,20,30,40,50$ and $60 \mathrm{mmol} / \mathrm{l}$ glucose) for $24 \mathrm{~h}$, and it was found that glucose induced cell cytotoxicity (Fig. 1A). A glucose concentration of $40 \mathrm{mmol} / \mathrm{l}$ was considered a suitable concentration for use in the following experiments. To examine the cytoprotective effect of Ang-(1-7) against HG-induced cytotoxicity in HUVECs, a dose-response study with varying doses of Ang-(1-7) $(0.5,1,2,4,6,8$ and $10 \mu \mathrm{M})$ was performed to calculate the cardioprotection dose of Ang-(1-7). As shown in Fig. 1B, exposure of the HUVECs to $40 \mathrm{mM}$ glucose (HG) for $24 \mathrm{~h}$ induced cytotoxicity, as indicated by the decrease in cell viability. However, the cytotoxic effect of HG on HUVECs was markedly inhibited by pre-treatment of the cells with Ang-(1-7) for $30 \mathrm{~min}$. The maximum inhibitory effect was observed with $2 \mu \mathrm{M}$ Ang-(1-7). Alone, $10 \mu \mathrm{M}$ Ang-(1-7) did not significantly alter the viability of the HUVECs. For this reason, the HUVECs were pre-treated with $2 \mu \mathrm{M}$ Ang-(1-7) for 30 min prior to exposure to $\mathrm{HG}$ in all subsequent experiments.

As shown in Fig. 1C, exposure of the HUVECs to HG for $24 \mathrm{~h}$ induced cytotoxicity, which led to a decrease in cell viability. However, this decreased cell viability was markedly repressed by pre-treatment with $2 \mu \mathrm{M}$ Ang-(1-7) or $20 \mu \mathrm{M}$ AG490. Alone, neither $2 \mu \mathrm{M}$ Ang-(1-7) or $20 \mu \mathrm{M}$ AG490 affected the viability of HUVECs.

JAK2 siRNA inhibits expression of the JAK2/STAT3 pathway and attenuates the HG-induced decrease in cell viability of HUVECs. To observe the effects of JAK2 siRNA on the expression of the JAK2/STAT3 pathway, the HUVECs were treated with JAK2 siRNA. As shown in Fig. 2, JAK2 siRNA significantly inhibited the expression levels of p-JAK2 (Fig. 2A and B) and p-STAT3 (Fig. 2C and D). In addition, JAK2 siRNA attenuated the HG-induced decrease in cell viability in the HUVECs, as shown in Fig. 2E.

$H G$ activates the JAK2/STAT3 pathway in HUVECs. The present study also examined the effects of HG on the STAT3/JAK2 pathway, including the phosphorylation of STAT3 and JAK2. As shown in Fig. 3A-D, the effect of glucose on the HUVECs were examined. The cells were exposed to the indicated concentrations $(20,30,40,50$ and $60 \mathrm{mM})$ of glucose for $24 \mathrm{~h}$, and exposure to glucose significantly upregulated the expression levels of (Fig. 3A and C) pSTAT3, peaking at $60 \mathrm{mM}$ glucose. However, the expression of t-STAT3 was not affected by the indicated concentrations of glucose. Based on these results, the effect of time on the expression of p-STAT3 was examined. As shown in Fig. 3B and D, following exposure of HUVECs to $40 \mathrm{mM}$ glucose for the indicated times $(3,6$, $12,18,24,36$ and $48 \mathrm{~h}$ ), the expression levels of p-STAT3 were 

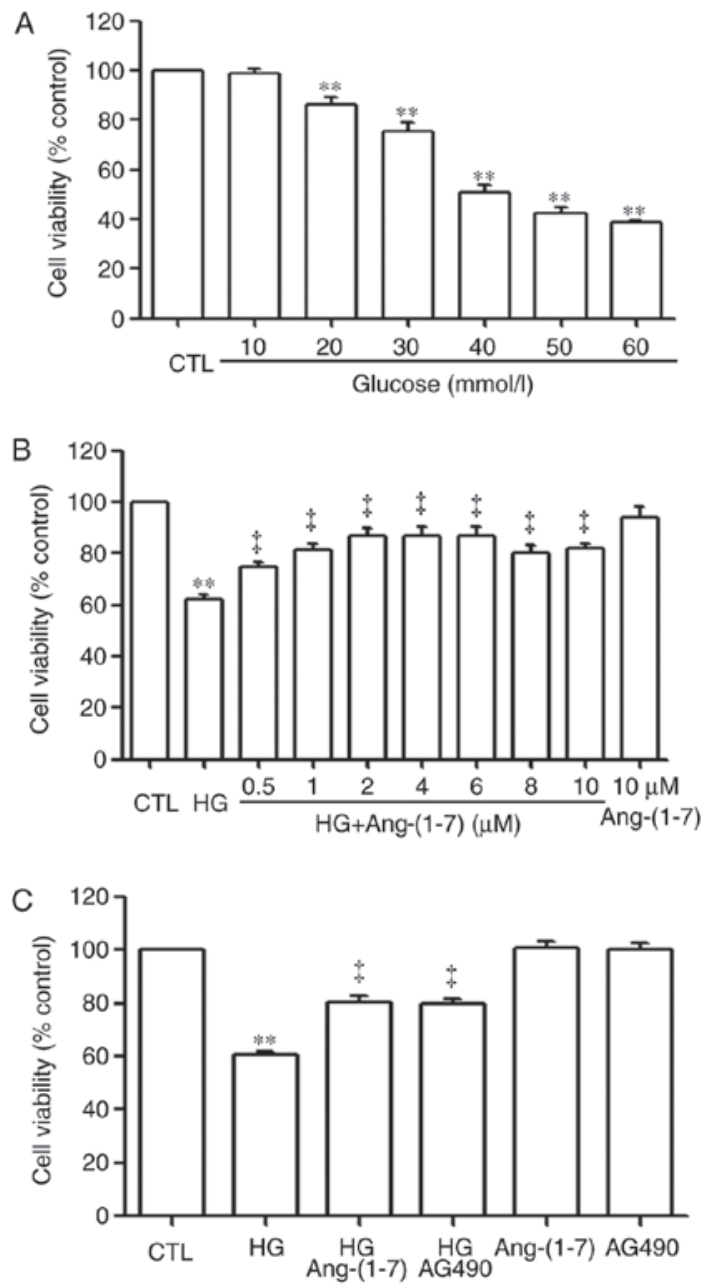

Figure 1. Ang-(1-7) and AG490 alleviate HG-induced cardiomyocyte cytotoxicity in HUVECs. Cell viability was detected using the Cell Counting Kit-8 assay. (A) HUVECs were treated with different concentrations of glucose $(10,20,30,40,50$ and $60 \mathrm{mmol} / 1$ glucose) for $24 \mathrm{~h}$. (B) HUVECs were treated with $\mathrm{HG}$ for $24 \mathrm{~h}$ in the absence or presence of pre-treatment with the indicated concentrations $(0.5,1,2,4,6,8$ and $10 \mu \mathrm{mol} / \mathrm{l})$ of Ang-(1-7) for $30 \mathrm{~min}$ prior to exposure of cells to HG for $24 \mathrm{~h}$. (C) Cells were pre-treated with or without $2 \mu \mathrm{mol} / 1$ Ang-(1-7) or $20 \mu \mathrm{mol} / 1$ AG490 (inhibitor of Janus kinase 2/signal transducer and activator of transcription 3 pathway) for $30 \mathrm{~min}$ prior to exposure of cells to $40 \mathrm{mM}$ glucose for $24 \mathrm{~h} .{ }^{* *} \mathrm{P}<0.01$, vs. CTL group; ${ }^{\circ} \mathrm{P}<0.01$, vs. HG group. $\mathrm{HG}$, high glucose ( $40 \mathrm{mM}$ glucose); Ang-(1-7), angiotensin-(1-7); HUVECs, human umbilical vein endothelial cells.

significantly upregulated, reaching a peak at $36 \mathrm{~h}$, whereas the expression of t-STAT3 remained unchanged. Similarly, exposure of the cells to $40 \mathrm{mM}$ glucose increased the expression levels of p-JAK2, as shown in the dose-response experiment (Fig. 3E) and time-response experiment (Fig. 3F), respectively. The mRNA expression levels of STAT3 (Fig. 3G) and JAK2 (Fig. 3H) were also markedly increased.

Ang-(1-7) downregulates HG-induced activation of the JAK2/STAT3 pathway in HUVECs. To observe effects of Ang-(1-7) on the activation of the JAK2/STAT3 pathway induced by $\mathrm{HG}$, the HUVECs were pre-treated with $2 \mu \mathrm{M}$ Ang-(1-7) for $30 \mathrm{~min}$, prior to exposure to $\mathrm{HG}$ for $24 \mathrm{~h}$. As shown in Fig. 4, exposure of the cells to $40 \mathrm{mM}$ glucose significantly increased the expression levels of p-STAT3 (Fig. 4A and B) and p-JAK2 (Fig. 4A and C). However, the increased
A
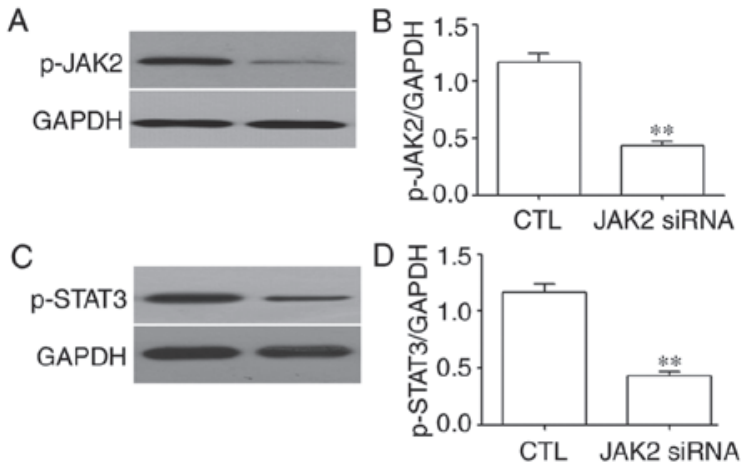

E

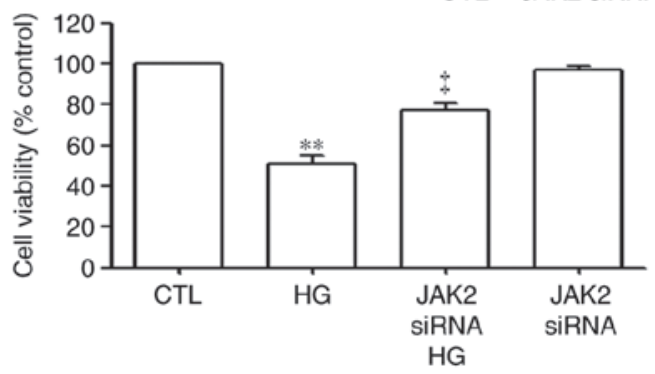

Figure 2. JAK2 siRNA inhibits the expression of JAK2/STAT3 and attenuates HG-induced decreased cell viability in HUVECs. HUVECs were exposed to JAK2 siRNA for $24 \mathrm{~h}$. Western blot analysis was performed to detect the expression levels of (A) JAK2 with (B) densitometric analysis, and for the expression of (C) STAT3 with (D) densitometric analysis. (E) Cells were co-conditioned with HG and JAK2 siRNA for $24 \mathrm{~h}$. Cell viability was detected using a Cell Counting Kit- 8 assay. ${ }^{* *} \mathrm{P}<0.01$ vs. CTL group. JAK2, Janus kinase 2; STAT3, signal transducer and activator of transcription 3; HUVECs, human umbilical vein endothelial cells; HG, high glucose; siRNA, small interfering RNA; CTL, control; p, phosphorylated.

phosphorylation of the JAK2/STAT3 pathway was reduced by pre-treatment with $2 \mu \mathrm{M}$ Ang-(1-7).

$H G$ upregulates the expression level of caspase-3 and downregulates the expression level of eNOS in HUVECs. The present study also examined the effects of HG on the expression levels of caspase-3 and eNOS in HUVECs. As shown in Fig. 5A and E, The HUVECs were exposed to (A) the indicated concentrations $(20,30,40,50$ and $60 \mathrm{mM})$ of glucose for $24 \mathrm{~h}$, or (B) with $40 \mathrm{mM}$ glucose for the indicated durations (3, $6,12,18,24,36$ and 48 h). (C) Exposure to different glucose concentrations markedly increased the expression levels of caspase-3, peaking at $60 \mathrm{mM}$ glucose. Based on these results, the effect of time on the expression was examined. As shown in Fig. 5D, when the HUVECs were exposed to $40 \mathrm{mM}$ glucose for the indicated durations $(3,6,12,18,24,36$ and $48 \mathrm{~h})$, the expression levels of caspase- 3 were significantly upregulated, reaching a peak at 12 and $18 \mathrm{~h}$. By contrast, exposure of the cells to HG decreased the expression levels of eNOS, as shown in the dose-response experiment (Fig. 5E) and time-response experiment (Fig. 5F), respectively.

Ang-(1-7) and AG490 downregulate the increased expression of caspase- 3 and upregulate the decreased expression of eNOS induced by HG in HUVECs. To observe the effects of Ang-(1-7) and AG490 on the increased expression level of caspase-3 and upregulating the decreased expression level of eNOS induced by HG, the HUVECs were pre-treated with $2 \mu \mathrm{M}$ Ang-(1-7), as shown in Fig. 6A-C, or $20 \mu \mathrm{M}$ AG490 for $30 \mathrm{~min}$ (Fig. 6D-F), prior to exposure to $\mathrm{HG}$ for 

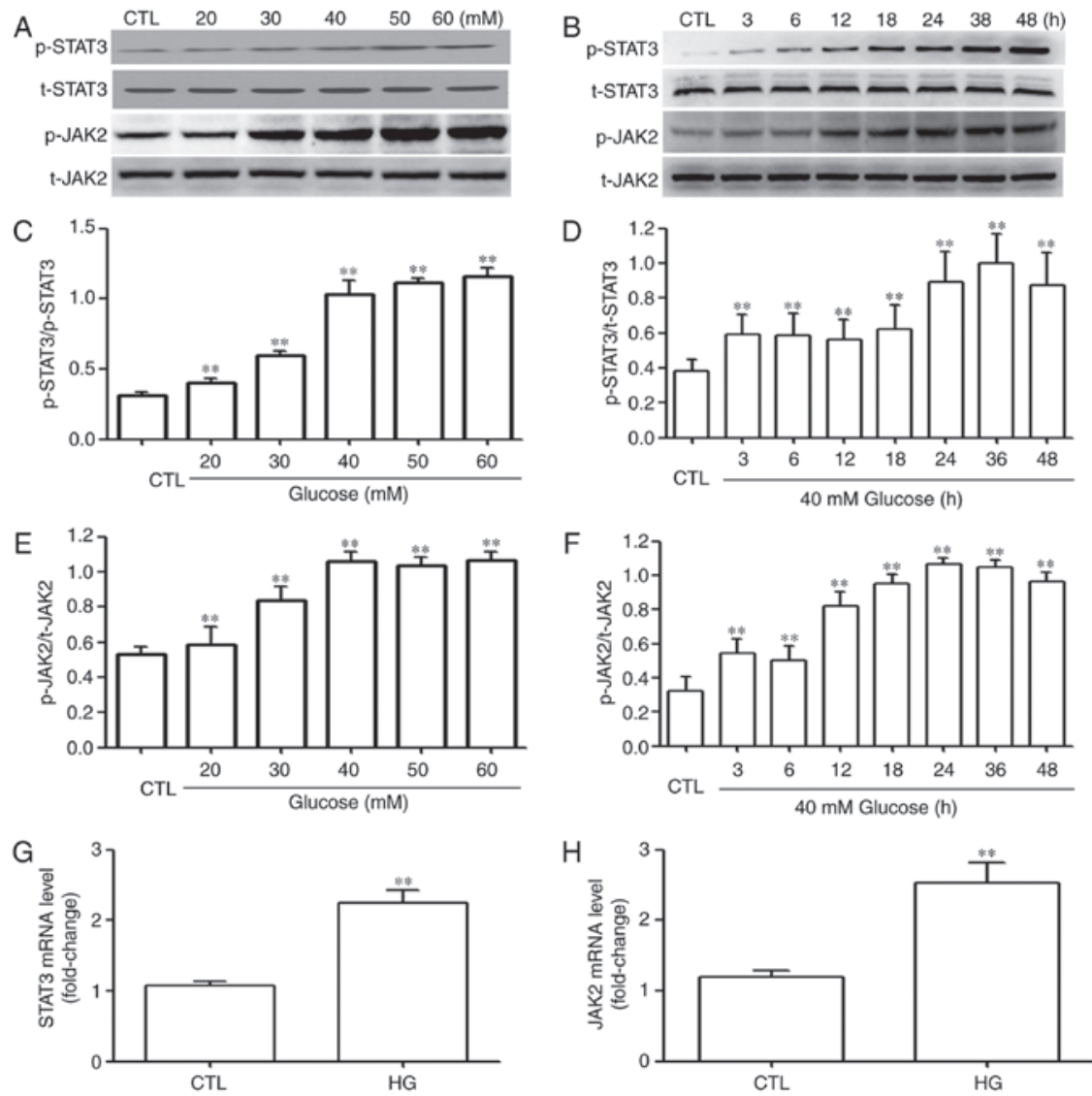

Figure 3. HG induces activation of the STAT3/JAK2 pathway in HUVECs. (A) HUVECs were exposed to the indicated concentrations of glucose (20, 30, 40, 50 and $60 \mathrm{mmol} / 1$, respectively) for $24 \mathrm{~h}$ or (B) were exposed to $\mathrm{HG}$ for the indicated durations $(3,6,12,18,24,36$ and $48 \mathrm{~h}$, respectively), followed by western blot analysis for the expression of STAT3 and JAK2. Densitometric analysis was performed to determine levels of (C and D) STAT3 and (E and F) JAK2 under different concentrations of glucose and different durations of HG, respectively. mRNA levels of (G) STAT3 and (H) JAK2 were assessed. "** P $<0.01$ vs. CTL group. JAK2, Janus kinase 2; STAT3, signal transducer and activator of transcription 3; HUVECs, human umbilical vein endothelial cells; HG, high glucose; siRNA, small interfering RNA; CTL, control; p, phosphorylated; t, total.
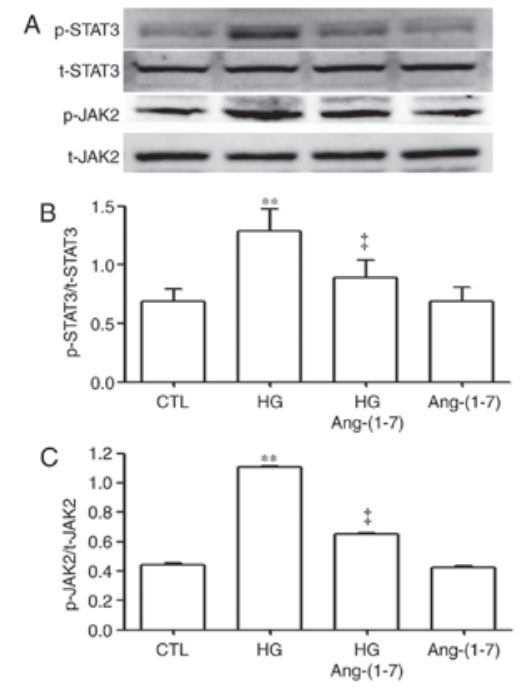

Figure 4. Ang-(1-7) ameliorates the phosphorylation of the STAT3/JAK2 pathway induced by HG in HUVECs. HUVECs were treated with HG in the absence or presence of co-treatment with $2 \mu \mathrm{mol} / 1$ Ang-(1-7) for $24 \mathrm{~h}$. (A) Expression levels of STAT3 and JAK2 were detected using western blot assays. (A) Densitometric analysis of changes in the expression levels of (B) STAT3 and (C) JAK2 in the indicated groups. ${ }^{* *} \mathrm{P}<0.01$, compared with the CTL group; ${ }^{\circ} \mathrm{P}<0.01$ vs. HG group. JAK2, Janus kinase 2; STAT3, signal transducer and activator of transcription 3; HUVECs, human umbilical vein endothelial cells; Ang-(1-7), angiotensin-(1-7); p, phosphorylated; t, total; $\mathrm{HG}$, high glucose (40 mmol/l glucose); CTL, control.
$24 \mathrm{~h}$. As shown in Fig. 6, exposure of the cells to $40 \mathrm{mM}$ glucose significantly increased the expression levels of caspase-3 (Fig. 6A, C, D and F). However, the increased expression level of caspase- 3 was reduced by pre-treatment with $2 \mu \mathrm{M}$ Ang-(1-7) (Fig. 6A and B) or $20 \mu \mathrm{M} \mathrm{AG490} \mathrm{(Fig.} \mathrm{6D} \mathrm{and} \mathrm{F)}$ for $30 \mathrm{~min}$ prior to exposure to HG for $24 \mathrm{~h}$. Secondly, the exposure of cells to $40 \mathrm{mM}$ glucose significantly decreased the expression levels of eNOS (Fig. 6A, B, D and E). However, the decreased expression levels of eNOS were upregulated following pre-treatment with $2 \mu \mathrm{M}$ Ang-(1-7) (Fig. 6A and B) or $20 \mu \mathrm{M}$ AG490 (Fig. 6D and E) for 30 min prior to exposure to $\mathrm{HG}$ for $24 \mathrm{~h}$.

Ang-(1-7) and AG490 suppress HG-induced apoptosis in HUVECs. As shown in Fig. 7Aa and b, exposure of HUVECs to $40 \mathrm{mM}$ glucose for $24 \mathrm{~h}$ induced typical apoptosis, which was manifested as the nuclear condensation and fragmentation condensation of chromatin, and the shrinkage of nuclei and apoptotic bodies. However, pre-treatment of the cells with $2 \mu \mathrm{M}$ Ang-(1-7) for $30 \mathrm{~min}$ prior to exposure to $\mathrm{HG}$ for $24 \mathrm{~h}$ mitigated the HG-induced increase in the number of cells undergoing apoptosis (Fig. 7Ac). In addition, pre-conditioning of the cells with $20 \mu \mathrm{M}$ AG490 for $30 \mathrm{~min}$ prior to exposure to $\mathrm{HG}$ for $24 \mathrm{~h}$ also ameliorated the HG-induced apoptosis of cardiac cells (Fig. 7Ad). Alone, $2 \mu \mathrm{M}$ Ang-(1-7) (Fig. 7Ae) or 

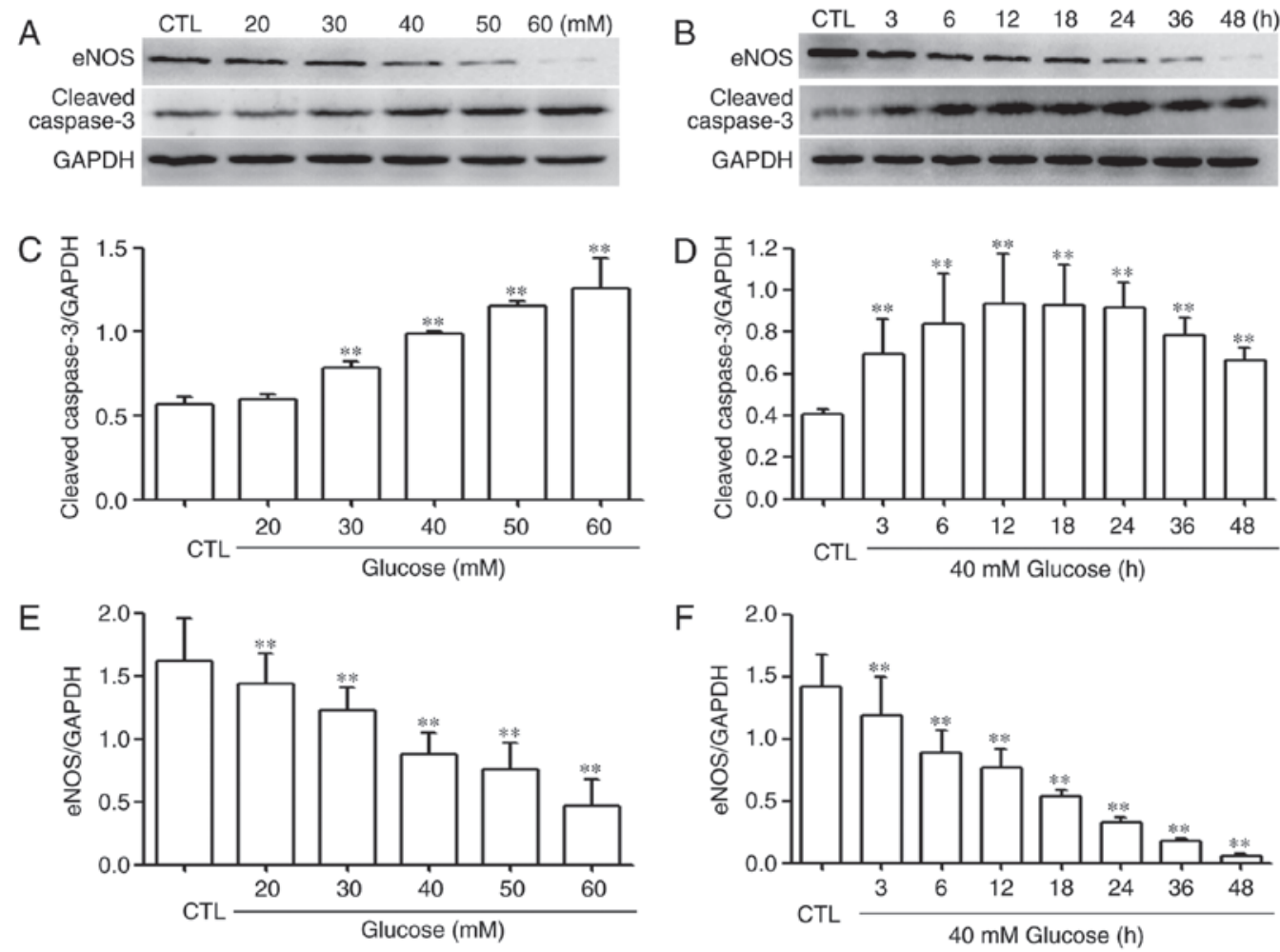

Figure 5. HG upregulates the expression levels of caspase- 3 and downregulates the expression levels of eNOS in HUVECs. HUVECs were exposed to (A) the indicated concentrations of glucose (20,30,40,50 and $60 \mathrm{mmol} / \mathrm{l}$, respectively) for $24 \mathrm{~h}$, or (B) HG for the indicated durations $(3,6,12,18,24,36 \mathrm{and} 48 \mathrm{~h}$, respectively). Expression levels of caspase-3 and eNOS were measured using western blot assays. Densitometric analysis of the expression of caspase-3 under (C) different glucose concentrations and (D) with HG for different durations. Densitometric analysis of the expression of eNOS under (E) different glucose concentrations and (F) with HG for different durations, respectively. ${ }^{* *} \mathrm{P}<0.01$ vs. CTL group. HUVECs, human umbilical vein endothelial cells; eNOS, endothelial nitric oxide synthase; Ang-(1-7), angiotensin-(1-7); GAPDH, glyceraldehyde-3-phosphate dehydrogenase; HG, high glucose (40 mmol/1 glucose); CTL, control.

$20 \mu \mathrm{M}$ AG490 (Fig. 7Af) did not significantly alter the number of apoptotic cells. Quantification of results is shown in Fig. 7B.

Ang-(1-7) and AG490 reduce the oxidative stress induced by $H G$ in HUVECs. The results demonstrated that oxidative stress contributed to HG-induced HUVEC injury. As shown in Figs. 8 and 9, exposure of the HUVECs to $40 \mathrm{mM}$ glucose for $24 \mathrm{~h}$ resulted in oxidative stress, as evidenced by an increase in the generation of ROS (Fig. 8Ab and B), a decrease in SOD activity (Fig. 9A) and increases in the expression level of Nox4 in the dose-response experiment $(20,30,40,50$ and $60 \mathrm{mM}$ glucose; Fig. 9B and C) and time-response experiment (3, 6, 12, 18, 24, 36 and 48 h; Fig. 9D and E). However, pre-treatment of the cells with $2 \mu \mathrm{M} \mathrm{Ang-(1-7)} \mathrm{for} 30 \mathrm{~min}$ prior to exposure to $\mathrm{HG}$ for $24 \mathrm{~h}$ mitigated the HG-induced increase in ROS generation (Fig. 8Ac and B), increased the HG-induced decrease in SOD activity (Fig. 9A) and decreased the expression level of Nox4 (Fig. 9F and G). To determine whether the JAK2/STAT3 pathway was involved in HG-induced oxidative stress, the HUVECs were pre-treated cells with $20 \mu \mathrm{M}$ AG490 for $30 \mathrm{~min}$ prior to exposure to HG for $24 \mathrm{~h}$. The resulting data showed that pre-treatment of the cells with $20 \mu \mathrm{M}$ AG490 for 30 min prior to exposure to HG for $24 \mathrm{~h}$ decreased the generation of ROS (Fig. 8Ad and B), upregulated SOD activity (Fig. 9A) and reduced the expression levels of Nox4 (Fig. 9F and G) in the HUVECs. Treatment with Ang-(1-7) or AG490 alone did not alter the basal level of ROS, activity of SOD or expression level of Nox4 in the HUVECs.
Ang-(1-7) and AG490 inhibit the HG-induced dissipation of MMP in HUVECs. It was shown that the exposure of HUVECs to $40 \mathrm{mM}$ glucose for $24 \mathrm{~h}$ elicited mitochondrial damage, as manifested by the dissipation of MMP (Fig. 10Aa and b). The dissipation of MMP was reduced by pre-treatment of the cells with $2 \mu \mathrm{M}$ Ang-(1-7) for $30 \mathrm{~min}$ prior to exposure to $\mathrm{HG}$ for $24 \mathrm{~h}$ (Fig. 10Ac), which demonstrated that Ang-(1-7) protected the HUVECs against HG-induced mitochondrial damage. Similarly, pre-treatment of HUVECs with $20 \mu \mathrm{M}$ AG490 for $30 \mathrm{~min}$ prior to exposure to $\mathrm{HG}$ for $24 \mathrm{~h}$ attenuated the HG-induced dissipation of MMP (Fig. 10Ad). The quantitative results are shown in Fig. 10B.

Ang-(1-7) and AG490 suppress the HG-induced increased production of pro-inflammatory cytokines in HUVECs. As shown in Fig. 11, the levels of IL-1 $\beta$ (Fig. 11A), IL-10 (Fig. 11B), IL-12 (Fig. 11C) and TNF- $\alpha$ (Fig. 11D) were markedly increased in the HG-induced HUVECs, compared with those in the control group $(\mathrm{P}<0.01)$. However, these increased levels of IL-1 $\beta$, IL-10, IL-12 and TNF- $\alpha$ were significantly suppressed by pre-treatment of the HUVECs with $2 \mu \mathrm{M}$ Ang-(1-7) for $30 \mathrm{~min}$ prior to exposure to HG for $24 \mathrm{~h}$. This suggested an inhibitory effect of Ang-(1-7) on the production of pro-inflammatory cytokines, including IL-1 $\beta$, IL-10, IL-12 and TNF- $\alpha$, induced by HG. Similarly, pre-treatment of the HUVECs with $20 \mu \mathrm{M}$ AG490 for 30 min prior to exposure to $\mathrm{HG}$ for $24 \mathrm{~h}$ decreased the enhanced production of IL-1 $\beta$, IL-10, IL-12 and TNF- $\alpha$. 
A

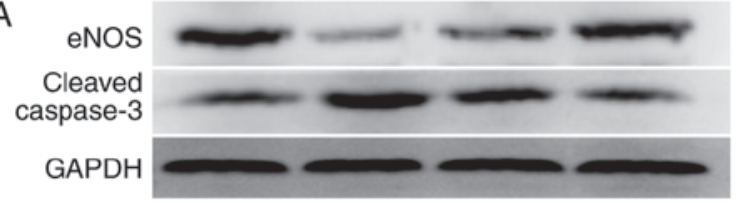

B
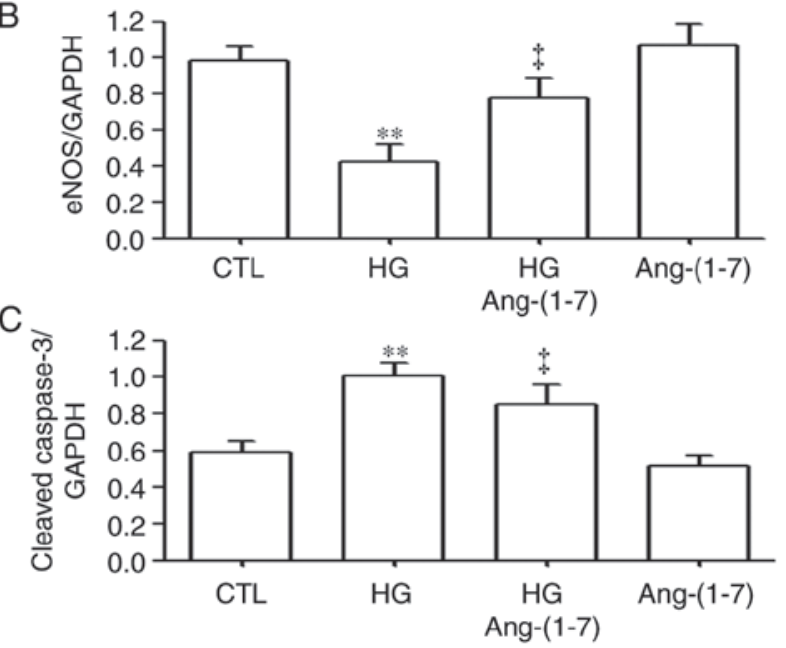

D

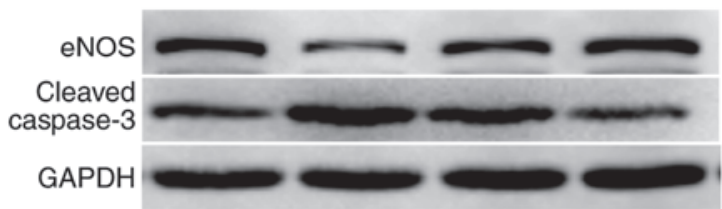

$\mathrm{E}$
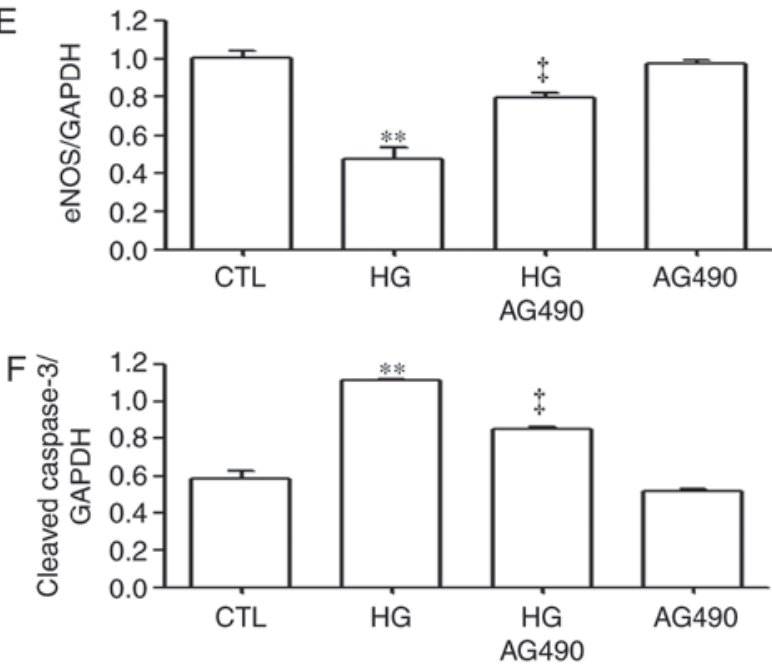

Figure 6. Ang-(1-7) and AG490 downregulate the increased expression level of caspase- 3 and upregulate the decreased expression level of eNOS induced by $\mathrm{HG}$ in human umbilical vein endothelial cells. Cells were co-conditioned with HG and $2 \mu \mathrm{mol} / 1$ Ang-(1-7) or $20 \mu \mathrm{mol} / 1$ AG490 (inhibitor of the Janus kinase 2/signal transducer and activator of transcription 3 pathway) for $24 \mathrm{~h}$. (A) Cells were treated with $2 \mu \mathrm{mol} / 1$ Ang-(1-7) followed by densitometric analysis of the expression of (B) eNOS and (C) caspase-3. (D) Cells were treated with $20 \mu \mathrm{mol} / 1 \mathrm{AG} 490$, followed by densitometric analysis for the expression of (E) eNOS and (F) caspase-3. ${ }^{* *} \mathrm{P}<0.01$ vs. CTL group; ${ }^{\star} \mathrm{P}<0.01$, compared with the HG-treated group. eNOS, endothelial nitric oxide synthase; Ang-(1-7), angiotensin-(1-7); GAPDH, glyceraldehyde-3-phosphate dehydrogenase; HG, high glucose (40 mmol/1 glucose); CTL, control.

\section{Discussion}

In the present study, the data revealed several novel findings indicating that the JAK2/STAT3 signaling pathway is relevant to the potential mechanisms responsible for $\mathrm{HG}$-induced HUVEC injury and inflammation, and the effect of Ang-(1-7) on protecting vascular endothelium. First, in the HUVECs, the JAK2/STAT3 signaling pathway was involved in the HG-induced HUVEC injury and inflammation. Secondly, Ang-(1-7) exerted endothelial protection against HG-induced injury and inflammation. Finally, the protective effects on the vascular endothelium by Ang-(1-7) were associated with inhibition of the JAK2/STAT3 pathway.

The data obtained demonstrated that the exposure of HUVECs to HG for $24 \mathrm{~h}$ led to injury and inflammation, as characterized by an increase in apoptotic cells, expression levels of caspase-3 (a death effector domain), oxidative stress (demonstrated by increased ROS production), decreased activation of SOD, increased expression of Nox4 (an important component of the NADPH oxidase family), increased expression level of eNOS, decreased cell viability and dissipation of MMP, and the upregulation of secretion of inflammatory cytokines (IL-1 $\beta, 11-6$, IL-12 and TNF- $\alpha$ ). These results are consistent with those of previous studies (5,6-9,29-31) and demonstrated that the damage in HG-induced HUVEC injury and inflammation was extensive. However, the associated mechanism remains to be fully elucidated.

The JAK2/STAT3 pathway is known to mediate survival signals, which contribute to cell proliferation, differentiation, growth and apoptosis (14-16). Similarly, the effects of the JAK2/STAT3 pathway on the cardiovascular system are also important and have been widely examined. Accumulating evidence has demonstrated that the JAK2/STAT3 pathway is involved in the progress of various stimulation-induced cardiovascular complication (32-36), including apoptosis $(32,33)$, reticulum stress $(32), \operatorname{ROS}(35,36)$, contractile dysfunction (36) and inflammation (37). Currently, the potential roles of the JAK2/STAT3 pathway in hyperglycemia-induced cardiovascular complication remain to be fully elucidated. Fiaschi et al identified a novel role for STAT3 as a crucial signaling molecule of collagen I production in cardiac fibroblasts induced by a diabetic environment (38). In addition, in streptozotocin (STZ)-induced diabetic rats, wortmannin (an inhibitor of PI3K) and AG490 (an inhibitor of JAK2), synergistically mitigate myocardial ischemia reperfusion injuries (39). This indicates that PI3K/Akt and JAK2/STAT3 are synergistically involved in myocardial injury in diabetes.

As the effects of the JAK2/STAT3 pathway in HG-induced HUVEC injury and inflammation remain to be fully elucidated, the present study aimed to elucidate the mechanism. Firstly, the role of HG on activation of the JAK2/STAT3 pathway in HUVECs was investigated. The results showed that exposure of the HUVECs to HG upregulated the expression levels of p-JAK2 and p-STAT3, indicating that HG activated the JAK2/STAT3 pathway in HUVECs. Secondly, the associated roles of JAK2/STAT3 pathway activation were examined in HG-stimulated injury. The data indicated that co-treatment of the HUVECs with HG and AG490, an inhibitor of the JAK2 pathway, significantly alleviated HG-induced injuries, including apoptosis, cytotoxicity, mitochondrial damage and oxidative stress, as evidenced by a decrease in the number of apoptotic cells, decreased expression levels of caspase-3 and Nox4, and an increase in the activation of SOD, cell viability, expression of eNOS and dissipation of MMP. These 

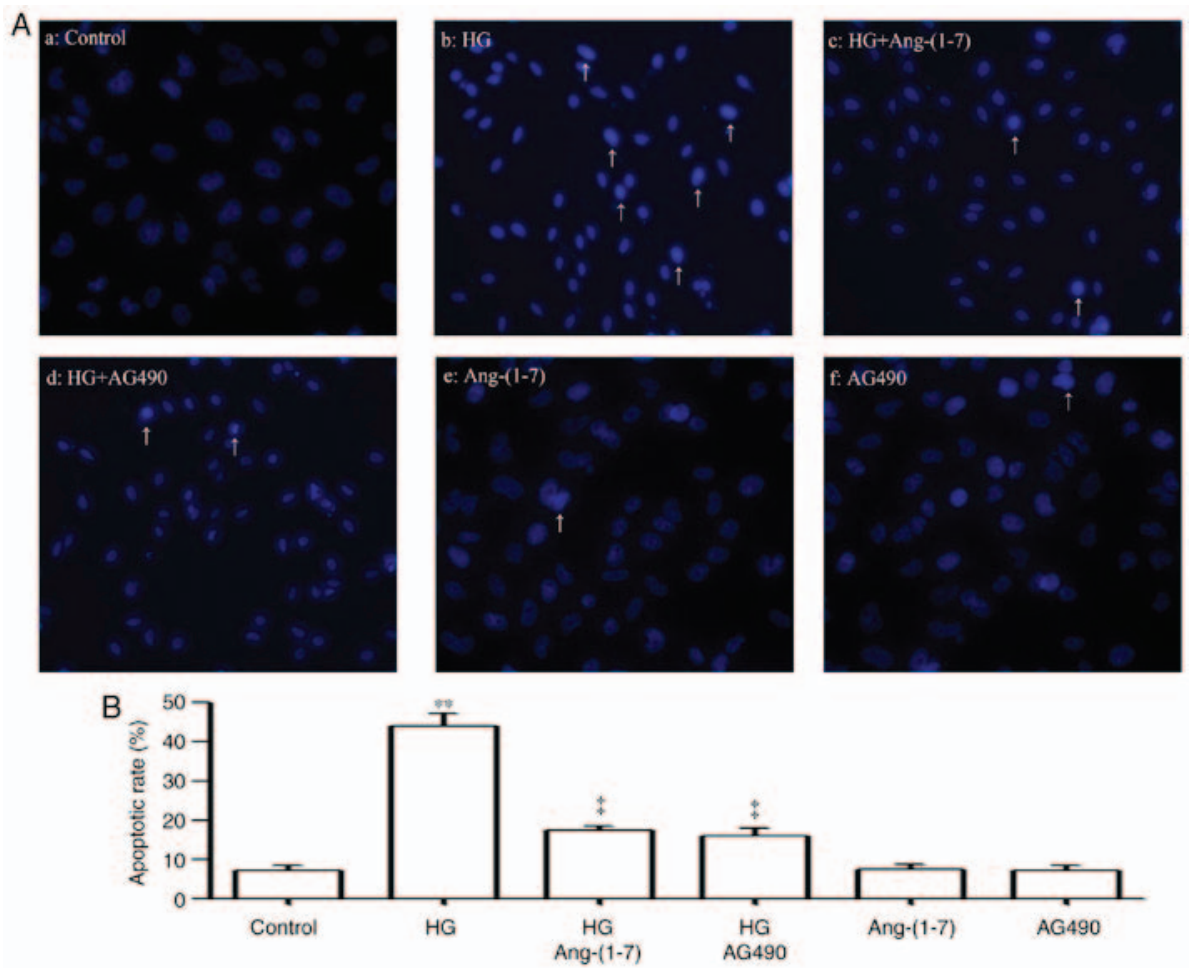

Figure 7. Ang-(1-7) and AG490 suppress HG-induced apoptosis in HUVECs. (A) Hoechst 33258 nuclear staining followed by fluorescence imaging was performed to examine cell apoptosis. (a) Control group; (b) HUVECs exposed to HG for 24 h; (c) HUVECs co-treated with HG and $2 \mu$ mol/l Ang-(1-7) for $24 \mathrm{~h}$; (d) HUVECs co-treated with HG and $20 \mu \mathrm{mol} / 1$ AG490 (inhibitor of the Janus kinase 2/signal transducer and activator of transcription 3 pathway) for $24 \mathrm{~h}$. (e) HUVECs treated with $2 \mu \mathrm{mol} / \mathrm{l} \mathrm{Ang-(1-7)} \mathrm{for} 24 \mathrm{~h}$; (f) HUVECs treated with $2 \mu \mathrm{mol} / \mathrm{l} \mathrm{Ang-(1-7)} \mathrm{for} 24 \mathrm{~h}$. (B) Apoptotic rates were analyzed using ImageJ $1.47 \mathrm{i}$ software. Images are captured at $\mathrm{x} 200$ magnification. ${ }^{* *} \mathrm{P}<0.01$ vs. CTL group; ${ }^{*} \mathrm{P}<0.01$, compared with the HG-treated group. HUVECs, human umbilical vein endothelial cells; Ang-(1-7), angiotensin-(1-7); HG, high glucose (40 mmol/l glucose); CTL, control.
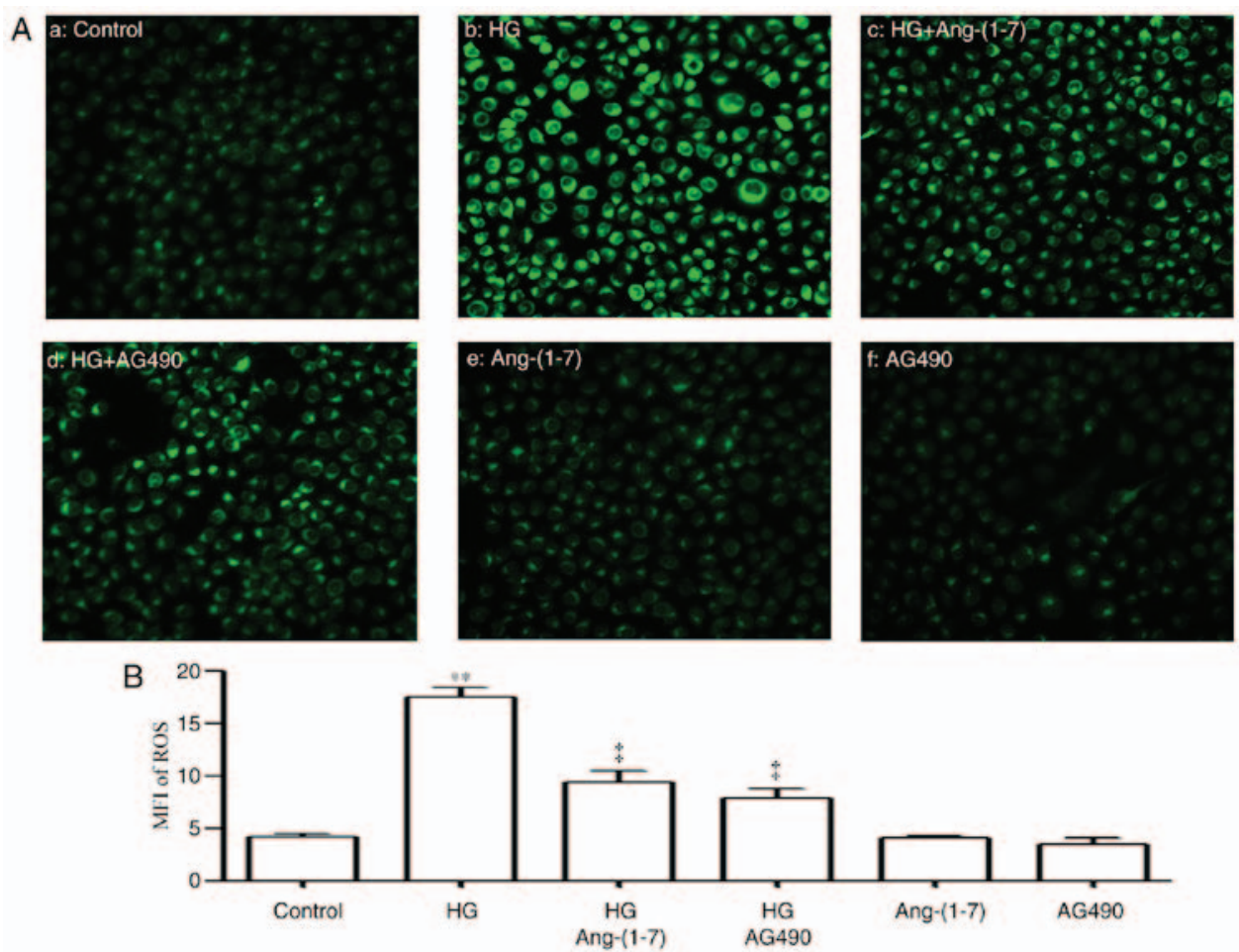

Figure 8. Ang-(1-7) and AG490 alleviate HG-induced increased ROS generation in HUVECs. (A) DCFH-DA staining followed by photofluorography was used to measure intracellular ROS levels. (a) Control group; (b) HUVECs exposed to HG for 24 h; (c) HUVECs co-treated with HG and $2 \mu$ mol/1 Ang-(1-7) for $24 \mathrm{~h}$; (D) HUVECs co-treated with HG and $20 \mu \mathrm{mol} / 1$ AG490 (inhibitor of the Janus kinase 2/signal transducer and activator of transcription 3 pathway) for $24 \mathrm{~h}$. (E) HUVECs treated with $2 \mu \mathrm{mol} / 1$ Ang-(1-7) for $24 \mathrm{~h}$; (F) HUVECs treated with $2 \mu \mathrm{mol} / 1$ Ang-(1-7) for $24 \mathrm{~h}$. (B) Quantitative analysis of the MFI of DCFH-DA using ImageJ $1.47 \mathrm{i}$ software. Images are captured at $\mathrm{X} 100$ magnification. ${ }^{* *} \mathrm{P}<0.01$, compared with the CTL group; ${ }^{\ddagger} \mathrm{P}<0.01$ vs. HG-treated group. HUVECs, human umbilical vein endothelial cells; Ang-(1-7), angiotensin-(1-7); HG, high glucose, 40 mmol/1 glucose; DCFH-DA, 2',7'-dichlorofluorescein diacetate; MFI, mean fluorescence intensity; ROS, reactive oxygen species; CTL, control. 

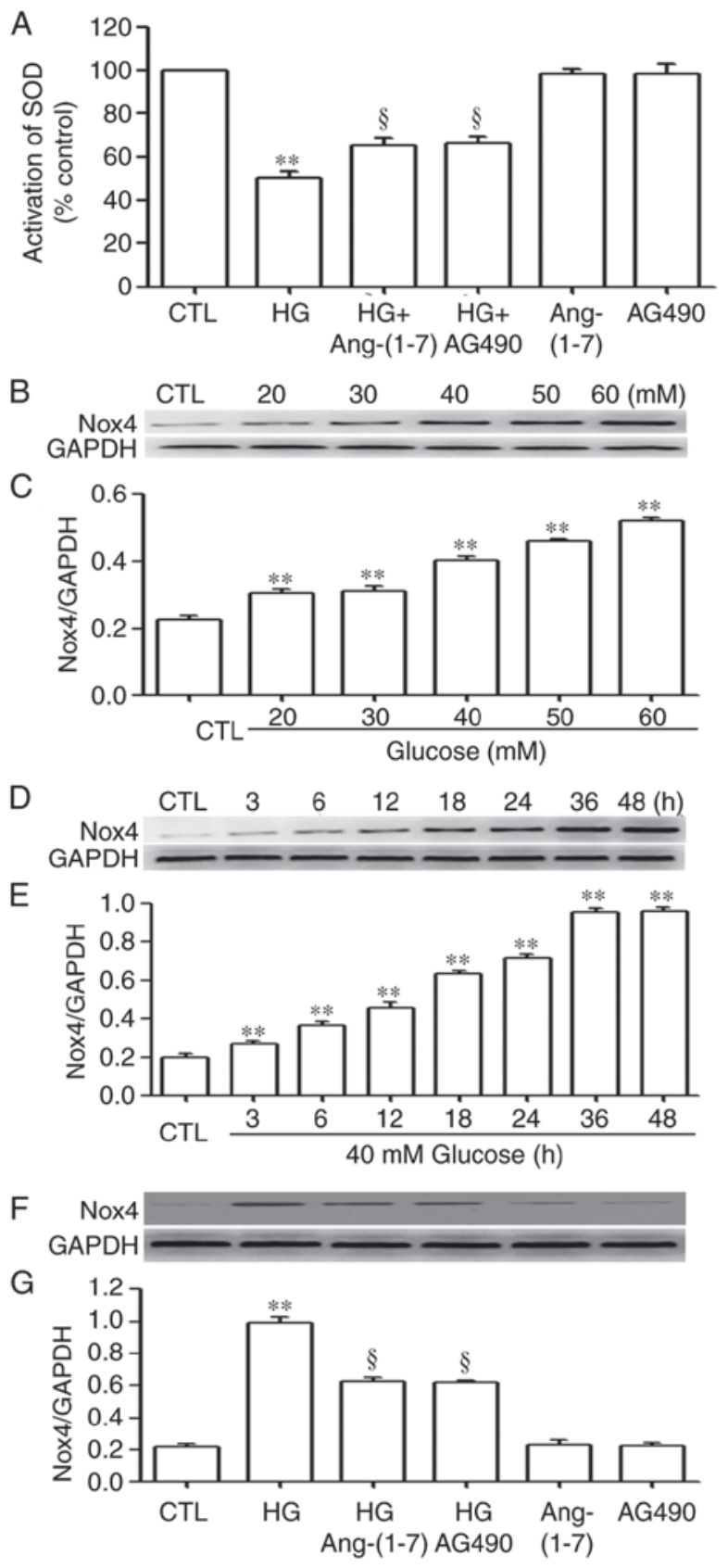

Figure 9. Ang-(1-7) and AG490 downregulate the increased expression level of Nox4 and increase SOD activity induced by HG in HUVECs. (A) SOD activity was examined using an SOD assay kit. (B) HUVECs were exposed to the indicated concentrations of glucose $(20,30,40,50$ and $60 \mathrm{mmol} / \mathrm{l}$, respectively) for $24 \mathrm{~h}$ and (C) levels of Nox 4 were determined using densitometric analysis. (D) HUVECs were exposed to $40 \mathrm{mM}$ glucose for the indicated times $(3,6,12,18,24,36$ and $48 \mathrm{~h}$, respectively) and (E) levels of Nox4 were determined using densitometric analysis. (F) HUVECs were co-conditioned with HG and $2 \mu \mathrm{mol} / 1$ Ang-(1-7) or $20 \mu \mathrm{mol} / 1$ AG490 (inhibitor of the Janus kinase 2/signal transducer and activator of transcription 3 pathway) for $24 \mathrm{~h}$, and $(\mathrm{G})$ expression levels of Nox 4 were measured using western blot analysis, followed by $(\mathrm{F})$ densitometric analysis. Data are presented as the mean \pm standard error of the mean $(\mathrm{n}=3) .{ }^{* *} \mathrm{P}<0.01$ vs. CTL group; ${ }^{*} \mathrm{P}<0.01$, compared with the HG-treated group. HUVECs, human umbilical vein endothelial cells; Ang-(1-7), angiotensin-(1-7); HG, high glucose (40 mmol/l glucose); Nox4, NADPH oxidase 4; SOD, superoxide dismutase; CTL, control.

results suggested that JAK2/STAT3 activation was involved in HG-stimulated injury in HUVECs. In addition, as it has been demonstrated that hyperglycemia is involved in vascular endothelium inflammation in vitro and in vivo (29,40-43), the present study further examined the role of JAK2/STAT3 activation on the HG-induced inflammatory response in HUVECs. Similar to the results of previous studies $(29,40-43)$, it was found that exposure of the HUVECs to HG promoted inflammatory responses, as indicated by the upregulated production of IL-1 $\beta$, IL-6, IL-12 and TNF- $\alpha$. However, the increased production of IL-1 $\beta$, IL-6, IL-12 and TNF- $\alpha$ was decreased by AG490. This suggested that the JAK2/STAT3 pathway was involved in the HG-induced production of pro-inflammatory factors (IL-1 $\beta$, IL-6, IL-12 and TNF- $\alpha$ ). The above data provide definitive and novel evidence that activation of the JAK2/STAT3 pathway contributed to HG-induced injury and inflammation in HUVECs.

An important finding of the present study relates to the various endothelial protective effects of Ang-(1-7) on HG-induced injury and inflammation in HUVECs. Firstly, it was found that Ang-(1-7) markedly alleviated HG-induced cytotoxicity, as characterized by increased cell viability. These results are supported by previous findings that toxicity induced by various factors, including lipopolysaccharide, long-term hypoxia and STZ-induced diabetes is alleviated by Ang-(1-7) (44-46). Secondly, Ang-(1-7) can exert anti-apoptotic effects against HG-induced apoptosis in HUVECs. According to previous studies, the anti-apoptotic effect of Ang-(1-7) is widely recognized, and is associated with various systems and organs, including the endocrine system (46), reproductive system (47), circulatory system (48), respiratory system (49), urinary system (50) and motor system (51). These data demonstrate that Ang-(1-7) protects cells against the injury induced by various factors by exerting anti-apoptotic effects. In the present study, data indicated that Ang-(1-7) protected the HUVECs against HG-induced apoptosis, as indicated by decreases in cell apoptosis and the expression of caspase-3. Ang-(1-7) is also involved in the oxidative stress induced by HG in HUVECs. In the circulatory system, Ang-(1-7) exerts cardiovascular protective effects by attenuating oxidative stress in cardiac (53), cardiomyocyte autophagy (52), hypertension (53) and vascular remodeling (54). Additionally, AVE0991, an analog of Ang-(1-7), attenuates cardiac hypertrophy via inhibiting oxidative stress (55). Ang-(1-7) also mediates the endothelial protection of signaling by reducing the oxidative stress induced by diabetes (56). Consistent with these previous findings, the results of the present study demonstrated that Ang-(1-7) protected HUVECs against HG-induced apoptosis by reducing oxidative stress, as characterized by a decrease in the production of ROS and expression level of Nox4, an important component of the NADPH oxidase family, and an increase in the activation of SOD. The findings of the present study also revealed that Ang-(1-7) had mitochondrial protective effects against HG-induced mitochondrial injury (a loss of MMP), which was comparable with a previous study showing that Ang-(1-7) alleviated the loss of MMP during $\mathrm{H}_{2} \mathrm{O}_{2}$-induced in pancreatic $\beta$ cells (57). The endothelial protective effect of Ang-(1-7) is also associated with its anti-inflammatory effect. In previous studies, Ang-(1-7) exerted anti-inflammatory effects in cardiomyocytes (58) and pulmonary microvascular endothelial cells (59) of the circulatory system. Similarly, the anti-inflammatory effect of Ang-(1-7) has been shown to contribute to endothelial protection in endothelial cells $(60,61)$. 

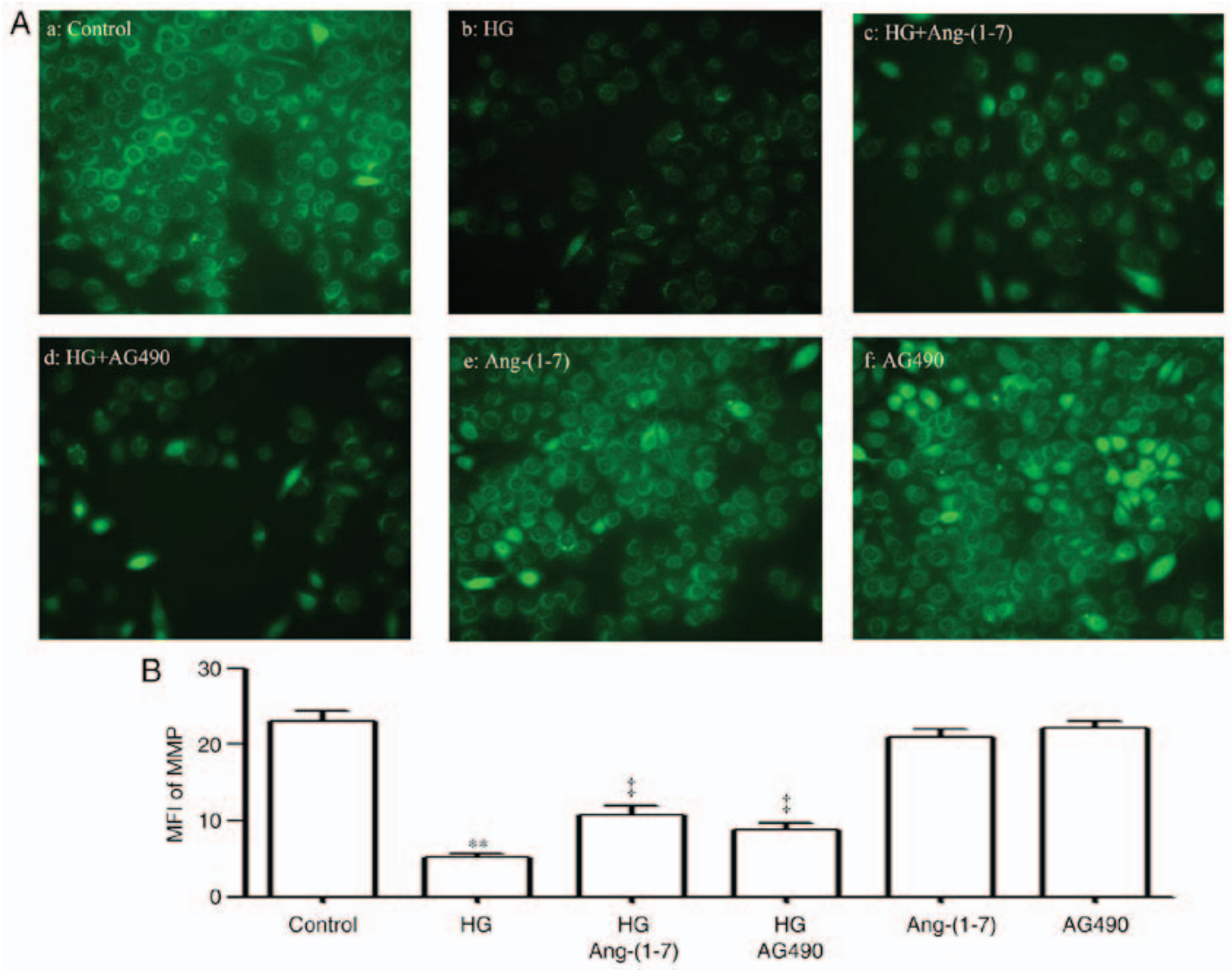

Figure 10. Ang-(1-7) and AG490 inhibit HG-induced dissipation of MMP in HUVECs. (A) Following the indicated treatments, MMP was assessed by Rh123 staining followed by photofluorography. (a) Control group; (b) HUVECs exposed to HG for 24 h; (c) HUVECs co-treated with HG and $2 \mu$ mol/1 Ang-(1-7) for $20 \mathrm{~h}$; (d) HUVECs co-treated with HG and $20 \mu \mathrm{mol} / 1 \mathrm{AG} 490$ (inhibitor of the Janus kinase 2/signal transducer and activator of transcription 3 pathway) for $24 \mathrm{~h}$; (e) HUVECs treated with $2 \mu \mathrm{mol} / 1$ Ang-(1-7) for $24 \mathrm{~h}$; (f) HUVECs treated with $2 \mu$ mol/1 Ang-(1-7) for 24 h. (B) Quantitative analysis of the MFI of Rh123 using ImageJ $1.47 \mathrm{i}$ software. Data are shown as the mean \pm standard error of the mean $(\mathrm{n}=3)$. ${ }^{* *} \mathrm{P}<0.01$, compared with the CTL group; ${ }^{\ddagger} \mathrm{P}<0.01$ vs. HG-treated group. HUVECs, human umbilical vein endothelial cells; MMP, mitochondrial membrane potential; Ang-(1-7), angiotensin-(1-7); HG, high glucose (40 mmol/l glucose); MFI, mean fluorescence intensity; CTL, control.

However, whether Ang-(1-7) inhibits HG-induced inflammation in HUVECs remains to be elucidated. In the present study, Ang-(1-7) significantly inhibited the HG-induced expression of inflammatory factors (IL-1 $\beta$, IL-6, IL-12 and TNF- $\alpha$ ). This indicates that the endothelial protective effect of Ang-(1-7) was involved in its anti-inflammatory effect. It was also found that Ang-(1-7) ameliorated the expression level of eNOS induced by HG in the HUVECs. Exposure of the HUVECs to HG for $24 \mathrm{~h}$ upregulated the expression level of eNOS. These data were supported by previous studies $(62,63)$. Co-treatment of the HUVECs with HG and Ang-(1-7) considerably elevated the expression level of eNOS. However, the association between Ang-(1-7) and eNOS remains to be elucidated and requires further investigation in vitro and in vivo.

Another important finding of the present study involves the effects of inhibition of the JAK2/STAT3 pathway on the endothelial protective effects of exogenous Ang-(1-7) against HG-induced multifarious endothelial cell injury and inflammation. Several studies have reported that Ang-(1-7) exerts endothelial protective effects $(44,47,55,58,59)$. The present study examined whether Ang-(1-7) protected HUVECs against HG-induced injury and inflammation by suppressing the JAK2/STAT3 pathway. The results demonstrated that exogenous Ang-(1-7) widely antagonized JAK2/STAT3 pathway activation and inflammatory factors (IL-1 $\beta$, IL-6, IL-12 and TNF- $\alpha$ ). In addition, similar to the inhibitory effects of AG490, an inhibitor of the JAK2 pathway, as indicated above, co-treatment of the HUVECs with HG and Ang-(1-7) mitigated HG-induced endothelial cell injury and inflammation. These results showed that the inhibitory effect of the JAK2/STAT3 pathway may be a crucial mechanism responsible for the endothelial protective effects of exogenous Ang-(1-7) against HG-induced endothelial cell injury and inflammation. Similarly, previous evidence demonstrates that exogenous Ang-(1-7) reduced Ang II-induced (25) or monocrotaline-induced (64) cell injury through inhibition of the JAK2/STAT3 pathway. Previous findings have also indicated that Ang-(1-7) exerts cardioprotective protection against HG-induced injury (65). These studies support the results of the present study.

In conclusion, the present study provided novel evidence that the JAK2/STAT3 pathway contributed to HG-induced endothelial cell injury and inflammation, and that exogenous Ang-(1-7) exerted endothelial protection against HG-induced endothelial cell injury and inflammation via the inhibitory effect on the JAK2/STAT3 pathways. These findings may assist in the development of novel therapeutic methods for the prevention and treatment of hyperglycemia-associated endothelial cell injury and inflammation. 

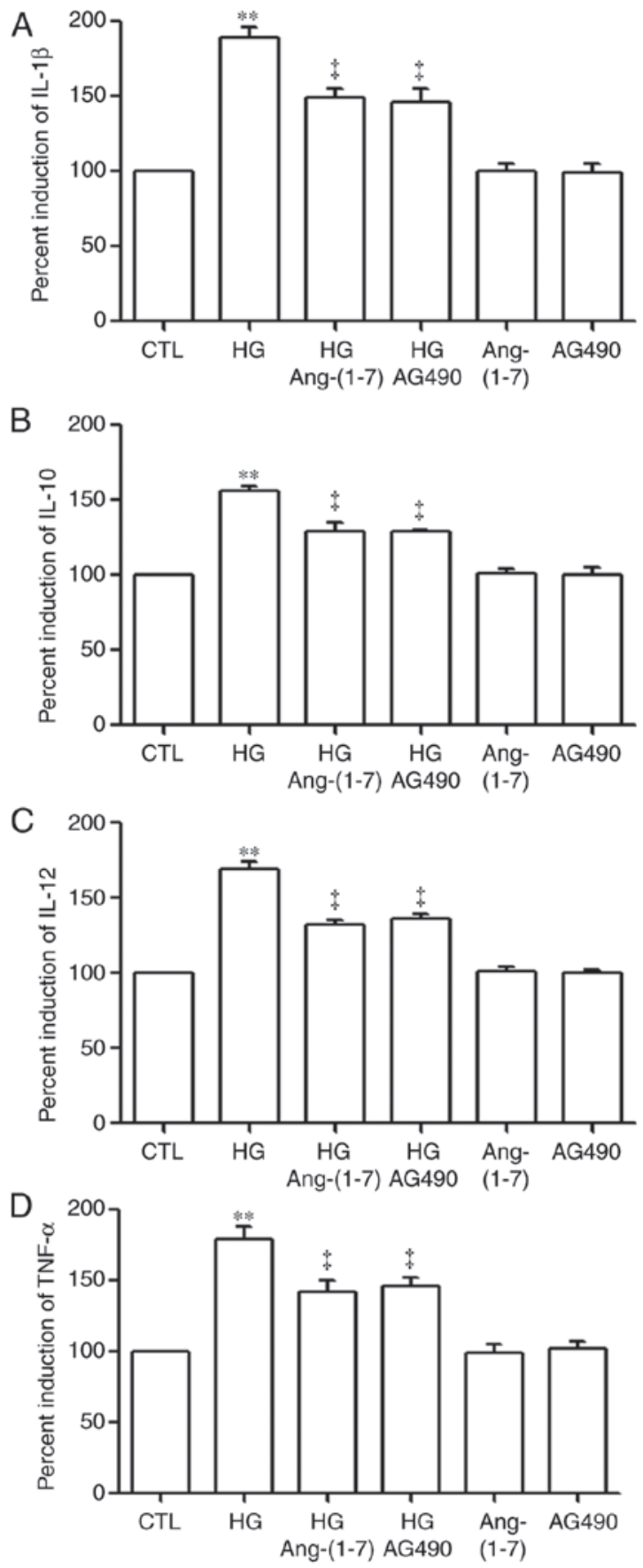

Figure 11. Ang-(1-7) and AG490 alleviate HG-induced production of IL-1 $\beta$, IL-10, IL-12 and TNF- $\alpha$ in human umbilical vein endothelial cells. The cells were treated with $\mathrm{HG}$ for $24 \mathrm{~h}$ with or without co-conditioning with $2 \mu \mathrm{mol} / 1$ Ang-(1-7) or $20 \mu \mathrm{mol} / 1$ AG490 (inhibitor of the Janus kinase 2/signal transducer and activator of transcription 3 pathway) for $24 \mathrm{~h}$. An enzyme-linked immunosorbent assay was performed to determine the levels of (A) IL-1 $\beta$, (B) IL-10, (C) IL-12 and (D) TNF- $\alpha$ in cell supernatants. Data are shown as the mean \pm standard error of the mean $(n=3) .{ }^{* *} \mathrm{P}<0.01$ vs. CTL group; ${ }^{\ddagger} \mathrm{P}<0.01$, compared with the HG-treated group. Ang-(1-7), angiotensin-(1-7); $\mathrm{HG}$, high glucose ( $40 \mathrm{mmol} / 1$ glucose). IL, interleukin; TNF- $\alpha$, tumor necrosis factor- $\alpha$; CTL, control.

\section{Acknowledgements}

The present study was supported by grants from the Guangdong Medical Research Foundation (grant no. A2012172), the Technology Planning Project of Huangpu District (grant no. 201544-01), the Science and Technology Planning Project of Guangdong Province, China (grant nos. 2012B031800358, 2012B031800365 and 2010B08071044), Medical Scientific Research Foundation of Guangdong Province (A2015287) and the Guangdong Natural Science Foundation (grant no. S2011010004381).

\section{Competing interests}

The authors declare that they have no competing interests.

\section{References}

1. Shaw JE, Sicree RA and Zimmet PZ: Global estimates of the prevalence of diabetes for 2010 and 2030. Diabetes Res Clin Pract 87: 4-14, 2010.

2. Guariguata L, Whiting DR, Hambleton I, Beagley J, Linnenkamp U and Shaw JE: Global estimates of diabetes prevalence for 2013 and projections for 2035. Diabetes Res Clin Pract 103: 137-149, 2014.

3. Bachmann KN and Wang TJ: Biomarkers of cardiovascular disease: Contributions to risk prediction in individuals with diabetes. Diabetologia, Sep 28, 2017 (Epub ahead of print).

4. Capellini VK, Celotto AC, Baldo CF, Olivon VC, Viaro F, Rodrigues AJ and Evora PR: Diabetes and vascular disease: Basic concepts of nitric oxide physiology, endothelial dysfunction, oxidative stress and therapeutic possibilities. Curr Vasc Pharmacol 8: 526-544, 2010.

5. Taguchi K, Sakata K, Ohashi W, Imaizumi T, Imura J and Hattori Y: Tonic inhibition by $\mathrm{G}$ protein-coupled receptor kinase 2 of Akt/endothelial nitric-oxide synthase signaling in human vascular endothelial cells under conditions of hyperglycemia with high insulin levels. J Pharmacol Exp Ther 349: 199-208, 2014.

6. Zhao H, Ma T, Fan B, Han C, Luo J and Kong L: Protective effect of trans- $\delta$-viniferin against high glucose-induced oxidative stress in human umbilical vein endothelial cells through the SIRT1 pathway. Free Radic Res 50: 68-83, 2016.

7. Zhang Y, Liu T, Chen Y, Dong Z, Zhang J, Sun Y, Jin B, Gao F, Guo S and Zhuang R: CD226 reduces endothelial cell glucose uptake under hyperglycemic conditions with inflammation in type 2 diabetes mellitus. Oncotarget 7: 12010-12023, 2016.

8. Bhatt MP, Lim YC, Hwang J, Na S, Kim YM and Ha KS: C-peptide prevents hyperglycemia-induced endothelial apoptosis through inhibition of reactive oxygen species-mediated transglutaminase 2 activation. Diabetes 62: 243-253, 2013.

9. Surico D, Farruggio S, Marotta P, Raina G, Mary D, Surico N, Vacca $\mathrm{G}$ and Grossini E: Human chorionic gonadotropin protects vascular endothelial cells from oxidative stress by apoptosis inhibition, cell survival signalling activation and mitochondrial function protection. Cell Physiol Biochem 36: 2108-2120, 2015.

10. Samanta A, Perazzona B, Chakraborty S, Sun X, Modi H, Bhatia R, Priebe W and Arlinghaus R: Janus kinase 2 regulates Bcr-Abl signaling in chronic myeloid leukemia. Leukemia 25: 463-472, 2011.

11. Kiu $\mathrm{H}$ and Nicholson SE: Biology and significance of the JAK/STAT signalling pathways. Growth Factors 30: 88-106, 2012.

12. Copf T, Goguel V, Lampin-Saint-Amaux A, Scaplehorn N and Preat T: Cytokine signaling through the JAK/STAT pathway is required for long-term memory in Drosophila. Proc Natl Acad Sci USA 108: 8059-8064, 2011.

13. Hiroi T, Wajima T, Kaneko Y, Kiuchi Y and Shimizu S: An important role of increase intetrahydrobiopterin via $\mathrm{H}_{2} \mathrm{O}_{2}$-JAK2 signaling pathway in late phase of ischaemic preconditioning. Exp Physiol 95: 609-621, 2010.

14. Qi QR and Yang ZM: Regulation and function of signal transducer and activator of transcription 3. World J Biol Chem 5: 231-239, 2014.

15. Corcoran RB, Contino G, Deshpande V, Tzatsos A, Conrad C, Benes CH, Levy DE, Settleman J, Engelman JA and Bardeesy N: STAT3 plays a critical role in KRAS-induced pancreatic tumorigenesis. Cancer Res 71: 5020-5029, 2011.

16. Aittomäki S and Pesu M: Therapeutic targeting of the Jak/STAT pathway. Basic Clin Pharmacol Toxicol 114: 18-23, 2014. 
17. Manea SA, Manea A and Heltianu C: Inhibition of JAK/STAT signaling pathway prevents high-glucose-induced increase in endothelin-1 synthesis in human endothelial cells. Cell Tissue Res 340: 71-79, 2010.

18. Amiri F, Venema VJ, Wang X, Ju H, Venema RC and Marrero MB: Hyperglycemia enhances angiotensin II-induced janus-activated kinase/STAT signaling in vascular smooth muscle cells. J Biol Chem 274: 32382-32386, 1999.

19. Hao PP, Chen YG, Liu YP, Zhang MX, Yang JM, Gao F, Zhang Y and Zhang C: Association of plasma angiotensin-(1-7) level and left ventricular function in patients with type 2 diabetes mellitus. PLoS One 8: e62788, 2013

20. Reich HN, Oudit GY, Penninger JM, Scholey JW and Herzenberg AM: Decreased glomerular and tubular expression of ACE2 in patients with type 2 diabetes and kidney disease. Kidney Int 74: 1610-1616, 2008.

21. Liu CX, Hu Q, Wang Y, Zhang W, Ma ZY, Feng JB, Wang R, Wang XP, Dong B, Gao F, et al: Angiotensin-converting enzyme (ACE) 2 overexpression ameliorates glomerular injury in a rat model of diabetic nephropathy: A comparison with ACE inhibition. Mol Med 17: 59-69, 2011.

22. Benter IF, Yousif MH, Cojocel C, Al-Maghrebi M and Diz DI: Angiotensin-(1-7) prevents diabetes-induced cardiovascular dysfunction. Am J Physiol Heart Circ Physiol 292: H666-H672, 2007.

23. Yousif MH, Dhaunsi GS, Makki BM, Qabazard BA, Akhtar S and Benter IF: Characterization of Angiotensin-(1-7) effects on the cardiovascular system in an experimental model of type-1 diabetes. Pharmacol Res 66: 269-275, 2012.

24. Hao PP, Yang JM, Zhang MX, Zhang K, Chen YG, Zhang C and Zhang Y: Angiotensin-(1-7) treatment mitigates right ventricular fibrosis as a distinctive feature of diabetic cardiomyopathy. Am J Physiol Heart Circ Physiol 308: H1007-H1019, 2015.

25. Kandalam U and Clark MA: Angiotensin II activates JAK2/STAT3 pathway and induces interleukin-6 production in cultured rat brainstem astrocytes. Regul Pept 159: 110-106, 2010

26. Mori J, Patel VB, Ramprasath T, Alrob OA, DesAulniers J, Scholey JW, Lopaschuk GD and Oudit GY: Angiotensin 1-7 mediates renoprotection against diabetic nephropathy by reducing oxidative stress, inflammation, and lipotoxicity. Am J Physiol Renal Physiol 306: F812-F821, 2014.

27. Livak KJ and Schmittgen TD: Analysis of relative gene expression data using real-time quantitative PCR and the $2^{-\Delta \Delta C_{\mathrm{T}}}$ method Methods 25: 402-408, 2001.

28. Huanga Z, Zhuanga X, Xieb C, Hua X, Donga X, Guoa Y, Lic $S$ and Liao X: Exogenous hydrogen sulfide attenuates high glucose-induced cardiotoxicity by inhibiting NLRP3 inflammasome activation by suppressing TLR4/NF-kB pathway in H9c2 Cells. Cell Physiol Biochem 40: v1578-v1590, 2016.

29. Ku SK and Bae JS: Baicalin, baicalein and wogonin inhibits high glucose-induced vascular inflammation in vitro and in vivo. BMB Rep 48: 519-524, 2015.

30. Chu P, Han G, Ahsan A, Sun Z, Liu S, Zhang Z, Sun B, Song Y, Lin Y, Peng J and Tang Z: Phosphocreatine protects endothelial cells from Methylglyoxal induced oxidative stress and apoptosis via the regulation of PI3K/Akt/eNOS and $N F-\kappa B$ pathway. Vascul Pharmacol 91: 26-35, 2017.

31. Wang XM, Song SS, Xiao H, Gao P, Li XJ and Si LY: Fibroblast growth factor 21 protects against high glucose induced cellular damage and dysfunction of endothelial nitric-oxide synthase in endothelial cells. Cell Physiol Biochem 34: 658-671, 2014.

32. Cui ZT, Liu JP and Wei WL: The effects of tanshinone IIA on hypoxia/reoxygenation-induced myocardial microvascular endothelial cell apoptosis in rats via the JAK2/STAT3 signaling pathway. Biomed Pharmacother 83: 1116-1126, 2016.

33. Jiang X, Guo CX, Zeng XJ, Li HH, Chen BX and Du FH: A soluble receptor for advanced glycation end-products inhibits myocardial apoptosis induced by ischemia/reperfusion via the JAK2/STAT3 pathway. Apoptosis 20: 1033-1047, 2015.

34. Zhao GL, Yu LM, Gao WL, Duan WX, Jiang B, Liu XD, Zhang B, Liu ZH, Zhai ME, Jin ZX, et al: Berberine protects rat heart from ischemia/reperfusion injury via activating JAK2/STAT3 signaling and attenuating endoplasmic reticulum stress. Acta Pharmacol Sin 37: 354-367, 2016.

35. Li L, Li M, Li Y, Sun W, Wang Y, Bai S, Li H, Wu B, Yang G, Wang $\mathrm{R}$, et al: Exogenous $\mathrm{H}_{2} \mathrm{~S}$ contributes to recovery of ischemic post-conditioning-induced cardioprotection by decrease of ROS level via down-regulation of NF- $\kappa$ B and JAK2-STAT3 pathways in the aging cardiomyocytes. Cell Biosci 6: 26, 2016.
36. Wu L, Tan JL, Wang ZH, Chen YX, Gao L, Liu JL, Shi YH, Endoh $M$ and Yang HT: ROS generated during early reperfusion contribute to intermittent hypobaric hypoxia-afforded cardioprotection against postischemia-induced $\mathrm{Ca}^{2+}$ overload and contractile dysfunction via the JAK2/STAT3 pathway. J Mol Cell Cardiol 81: 150-161, 2015.

37. Ni CW, Hsieh HJ, Chao YJ and Wang DL: Interleukin-6-induced JAK2/STAT3 signaling pathway in endothelial cells is suppressed by hemodynamic flow. Am J Physiol Cell Physiol 287: C771-C780, 2004

38. Fiaschi T, Magherini F, Gamberi T, Lucchese G2, Faggian G2, Modesti A and Modesti PA: Hyperglycemia and angiotensin II cooperate to enhance collagen I deposition by cardiac fibroblasts through a ROS-STAT3-dependent mechanism. Biochim Biophys Acta 1843: 2603-2610, 2014.

39. Wang T, Mao X, Li H, Qiao S, Xu A, Wang J, Lei S, Liu Z, Ng KF, Wong GT, et al: N-Acetylcysteine and allopurinol up-regulated the Jak/STAT3 and PI3K/Akt pathways via adiponectin and attenuated myocardial postischemic injury in diabetes. Free Radic Biol Med 63: 291-303, 2013

40. Hein TW, Xu W, Xu X and Kuo L: Acute and chronic hyperglycemia elicit JIP1/JNK-mediated endothelial vasodilator dysfunction of retinal arterioles. Invest Ophthalmol Vis Sci 57: 4333-4340, 2016

41. Wu N, Shen H, Liu H, Wang Y, Bai Y and Han P: Acute blood glucose fluctuation enhances rat aorta endothelial cell apoptosis, oxidative stress and pro-inflammatory cytokine expression in vivo. Cardiovasc Diabetol 15: 109, 2016.

42. Pollack RM, Donath MY, LeRoith D and Leibowitz G: Anti-inflammatory agents in the treatment of diabetes and its vascular complications. Diabetes Care 39 (Suppl 2): S244-S252, 2016.

43. Halvorsen B, Santilli F, Scholz H, Sahraoui A, Gulseth HL, Wium C, Lattanzio S, Formoso G, Di Fulvio P, Otterdal K, et al: LIGHT/TNFSF14 is increased in patients with type 2 diabetes mellitus and promotes islet cell dysfunction and endothelial cell inflammation in vitro. Diabetologia 59: 2134-2144, 2016.

44. Li Y, Zeng Z, Li Y, Huang W, Zhou M, Zhang X and Jiang W: Angiotensin-converting enzyme inhibition attenuates lipopolysaccharide-induced lung injury by regulating the balance between angiotensin-converting enzyme and angiotensin-converting enzyme 2 and inhibiting mitogen-activated protein kinase activation. Shock 43: 395-404, 2015.

45. Gopallawa I and Uhal BD: Angiotensin-(1-7)/mas inhibits apoptosis in alveolar epithelial cells through upregulation of MAP kinase phosphatase-2. Am J Physiol Lung Cell Mol Physiol 310: L240-L248, 2016.

46. He J, Yang Z, Yang H, Wang L, Wu H, Fan Y, Wang W, Fan X and Li X: Regulation of insulin sensitivity, insulin production, and pancreatic $\beta$ cell survival by angiotensin-(1-7) in a rat model of streptozotocin-induced diabetes mellitus. Peptides 64: 49-54, 2015.

47. Al-Maghrebi M and Renno WM: The ACE/Angiotensin (1-7)/mas axis protects against testicular ischemia reperfusion injury. Urology 94: 312.e1-8, 2016.

48. Yang HY, Bian YF, Zhang HP, Gao F, Xiao CS, Liang B, Li J, Zhang NN and Yang ZM: Angiotensin-(1-7) treatment ameliorates angiotensin II-induced apoptosis of human umbilical vein endothelial cells. Clin Exp Pharmacol Physiol 39: 1004-1010, 2012.

49. Ma X, Xu D, Ai Y, Zhao S, Zhang L, Ming G and Liu Z: Angiotensin-(1-7)/mas signaling inhibits lipopolysaccharide-induced ADAM17 shedding activity andapoptosis in alveolar epithelial cells. Pharmacology 97: 63-71, 2016.

50. Kim CS, Kim IJ, Bae EH, Ma SK, Lee J and Kim SW: Angiotensin-(1-7) attenuates kidney injury due to obstructive nephropathy in rats. PLoS One 10:e0142664, 2015.

51. Meneses C, Morales MG, Abrigo J, Simon F, Brandan E and Cabello-Verrugio C: The angiotensin-(1-7)/Mas axis reduces myonuclear apoptosis during recovery from angiotensin II-induced skeletal muscle atrophy in mice. Pflugers Arch 46: 1975-1984, 2015

52. Lin L, Liu X, Xu J, Weng L, Ren J, Ge J and Zou Y: Mas receptor mediates cardioprotection of angiotensin-(1-7) against Angiotensin II-induced cardiomyocyte autophagy and cardiac remodelling through inhibition of oxidative stress. J Cell Mol Med 20: 48-57, 2016.

53. Shi Y,Lo CS, Padda R, Abdo S, Chenier I, Filep JG, Ingelfinger JR, Zhang SL and Chan JS: Angiotensin-(1-7) prevents systemic hypertension, attenuates oxidative stress and tubulointerstitial fibrosis, and normalizes renal angiotensin-converting enzyme 2 and Mas receptor expression in diabetic mice. Clin Sci 128: 649-663, 2015. 
54. McKinney CA, Fattah C, Loughrey CM, Milligan G and Nicklin SA: Angiotensin-(1-7) and angiotensin-(1-9): Function in cardiac and vascular remodelling. Clin Sci 126: 815-827, 2014.

55. Ma Y, Huang H, Jiang J, Wu L, Lin C, Tang A, Dai G, He J and Chen Y: AVE 0991 attenuates cardiac hypertrophy through reducing oxidative stress. Biochem Biophys Res Commun 474: 621-625, 2016.

56. Zhang Y, Liu J, Luo JY, Tian XY, Cheang WS, Xu J, Lau CW, Wang L, Wong WT, Wong CM, et al: Upregulation of angiotensin (1-7)-mediated signaling preserves endothelial function through reducing oxidative stress in diabetes. Antioxid Redox Signal 23: 880-892, 2015.

57. Zhang F, Liu C, Wang L, Cao X, Wang YY and Yang JK: Antioxidant effect of angiotensin (1-7) in the protection of pancreatic $\beta$ cell function. Mol Med Rep 14: 1963-1969, 2016.

58. Papinska AM, Mordwinkin NM, Meeks CJ, Jadhav SS1 and Rodgers KE: Angiotensin-(1-7) administration benefits cardiac, renal and progenitor cell function in $\mathrm{db} / \mathrm{db}$ mice. $\mathrm{Br} \mathrm{J}$ Pharmacol, Jun 15, 2015 (Epub ahead of print).

59. Li Y, Cao Y, Zeng Z, Liang M, Xue Y, Xi C, Zhou M and Jiang W: Angiotensin-converting enzyme 2/angiotensin-(1-7)/Mas axis prevents lipopolysaccharide-induced apoptosis of pulmonary microvascular endothelial cells by inhibiting JNK/NF- $\kappa \mathrm{B}$ pathways. Sci Rep 5: 8209, 2015.

60. Zhang YH, Zhang YH, Dong XF, Hao QQ, Zhou XM, Yu QT Li SY, Chen X, Tengbeh AF, Dong B and Zhang Y: ACE2 and Ang-(1-7) protect endothelial cell function and prevent early atherosclerosis by inhibiting inflammatory response. Inflamm Res 64: 253-260, 2015.
61. Wang L, Hu X, Zhang W and Tian F: Angiotensin (1-7) ameliorates angiotensin II-induced inflammation by inhibiting LOX-1 expression. Inflamm Res 62: 219-228, 2013.

62. Yu JW, Deng YP, Han X, Ren GF, Cai J and Jiang GJ: Metformin improves the angiogenic functions of endothelial progenitor cells via activating AMPK/eNOS pathway in diabetic mice. Cardiovasc Diabetol 15: 88, 2016.

63. Bretón-Romero R, Feng B, Holbrook M, Farb MG, Fetterman JL, Linder EA, Berk BD, Masaki N, Weisbrod RM, Inagaki E, et al: Endothelial dysfunction in human diabetes is mediated by Wnt5a-JNK signaling. Arterioscler Thromb Vasc Biol 36: 561-569, 2016.

64. Haga S, Tsuchiya H, Hirai T, Hamano T, Mimori A and Ishizaka Y: A novel ACE2 activator reduces monocrotaline-induced pulmonary hypertension by suppressing the JAK/STAT and TGF- $\beta$ cascades with restored caveolin-1 expression. Exp Lung Res 41: 21-31, 2015

65. Lei Y, Xu Q, Zeng B, Zhang W, Zhen Y, Zhai Y, Cheng F, Mei W, Zheng D, Feng J, et al: Angiotensin-(1-7) protects cardiomyocytes against high glucose-induced injuries through inhibiting reactive oxygen species-activated leptin-p38 mitogen-activated protein kinase/extracellular signal-regulated protein kinase $1 / 2$ pathways, but not the leptin-c-Jun N-terminal kinase pathway in vitro. J Diabetes Investig 8: 434-445, 2017. 